\title{
Kras and Tumor Immunity: Friend or Foe?
}

\author{
Jane Cullis, ${ }^{1}$ Shipra Das, ${ }^{1}$ and Dafna Bar-Sagi \\ Department of Biochemistry and Molecular Pharmacology, New York University School of Medicine, \\ New York, New York 10016 \\ Correspondence: dafna.bar-sagi@nyumc.org
}

With the recent breakthroughs in immunotherapy as curative treatments in certain tumor types, there has been renewed interest in the relationship between immunity and tumor growth. Although we are gaining a greater understanding of the complex interplay of immune modulating components in the tumor microenvironment, the specific role that tumor cells play in shaping the immune milieu is still not well characterized. In this review, we focus on how mutant Kras tumor cells contribute to tumor immunity, with a specific focus on processes induced directly or indirectly by the oncogene.

t is well recognized that the growth of mutant Kras tumors is associated with an immunosuppressed state that is established via the dynamic interplay between components of both the innate and adaptive immune response (Fig. 1). For example, immunosuppressive cells commonly associated with mutant Kras tumors include myeloid cells, such as alternatively activated (M2) macrophages and myeloid-derived suppressor cells (MDSCs), as well as lymphoid cells, such as interleukin (IL)-17-producing $\mathrm{T}$ helper (Th) 17 cells, $\mathrm{CD}^{+} \mathrm{FoxP}^{+} \mathrm{T}$ regulatory (Treg) cells, and $\mathrm{CD} 19^{+} \mathrm{IL}-10^{+} \mathrm{B}$ regulatory (Breg) cells (Almand et al. 2001; Gabrilovich et al. 2001; Kusmartsev and Gabrilovich 2006). These cell types contribute to the suppression of tumoricidal cells such as $\mathrm{CD} 4^{+} \mathrm{Th} 1 \mathrm{~T}$ cells, natural killer (NK) cells, and $\mathrm{CD}^{+}{ }^{+} \mathrm{T}$ cytotoxic $(\mathrm{Tc})$ cells (Drake et al. 2006). The relative balance of these two antagonistic immune subpopulations profoundly impacts not only disease establish- ment and progression but also sensitivity to immunotherapy (Topalian et al. 2012; Pauken et al. 2015). In the sections that follow, we will elaborate on how mutant Kras-regulated signaling pathways affect the presence and function of these immune cell types. Moreover, we will describe how this contributes to the tumorigenic potential of Kras-mutant cancers with specific focus on pancreatic ductal adenocarcinoma (PDAC) and non-small-cell lung cancer (NSCLC), tumor types that harbor Kras mutations in more than $95 \%$ and $35 \%$ of cases, respectively (Seo et al. 2012; Rishi et al. 2015).

\section{KRAS’ IMMUNOLOGISTICS}

The discovery that oncogenic Kras could induce nuclear factor (NF)- $\kappa \mathrm{B}$ activation in fibroblasts and epithelial cells provided the first direct evidence of its capacity to drive proinflammatory signaling in transformed cells (Finco et al. 1997;

\footnotetext{
${ }^{1}$ These authors contributed equally to this work.

Editors: Linda VanAelst, Julian Downward, and Frank McCormick

Additional Perspectives on Ras and Cancer in the 21st Century available at www.perspectivesinmedicine.org

Copyright (C) 2018 Cold Spring Harbor Laboratory Press; all rights reserved; doi: 10.1101/cshperspect.a031849

Cite this article as Cold Spring Harb Perspect Med 2018;8:a031849
} 
J. Cullis et al.

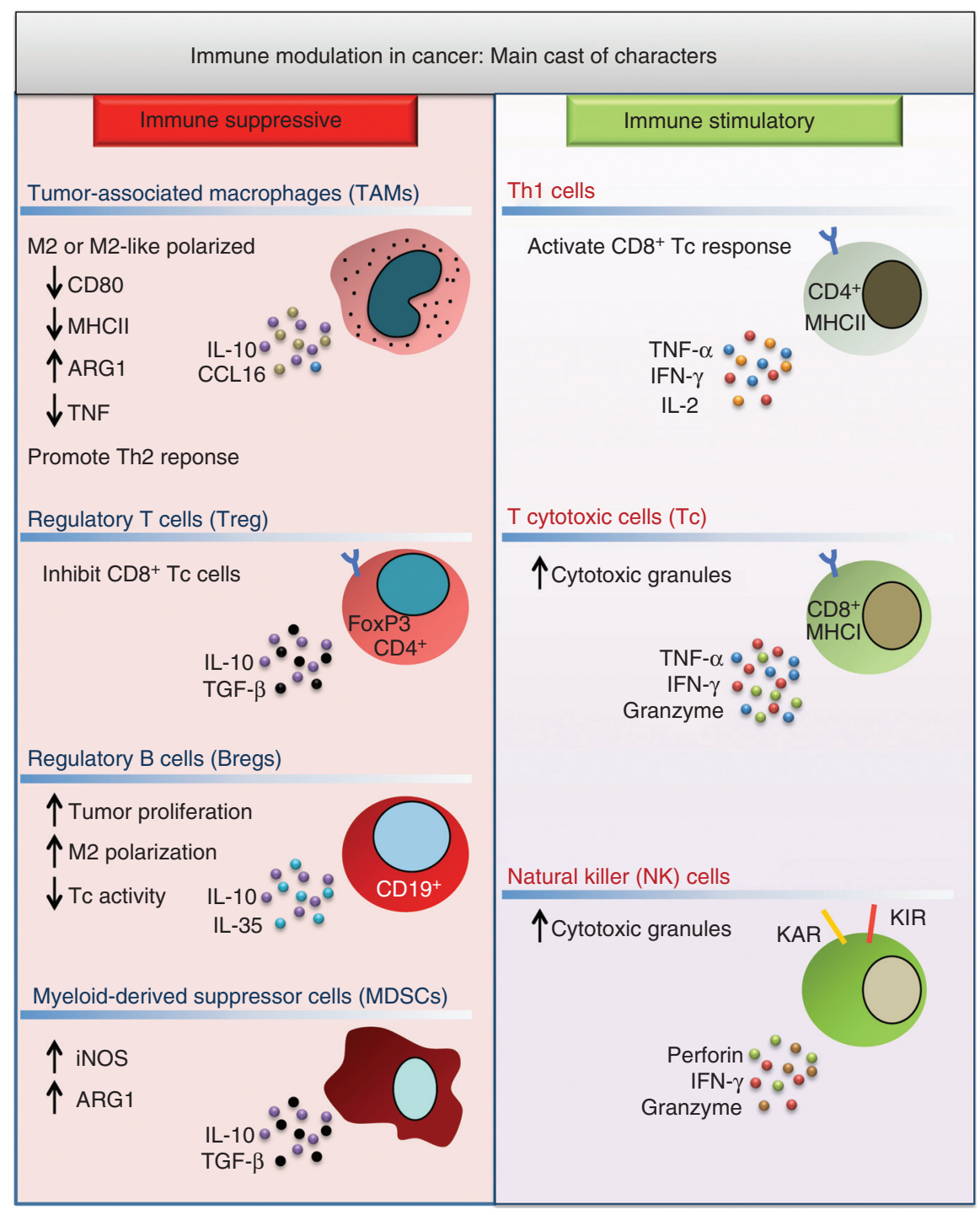

Figure 1. Main mediators of immune modulation in the tumor microenvironment (TME). Tumor-associated macrophages (TAMs), regulatory T (Treg) cells, regulatory B (Breg) cells, and myeloid-derived suppressor cells (MDSCs) induce a tumor-tolerant microenvironment through production of immune suppressive cytokines like interleukin (IL)-10, IL-35, and transforming growth factor $\beta$ (TGF- $\beta$ ). These factors antagonize the tumoricidal activity of T helper (Th)1 cells, T cytotoxic (Tc) cells, and natural killer (NK) cells that produce immune stimulatory cytokines and cytolytic factors. MHC, Major histocompatibility complex; iNOS, inducible nitric oxide synthase; ARG1, arginase 1; TNF- $\alpha$, tumor necrosis factor $\alpha$; IFN- $\gamma$, interferon $\gamma$.

Kim et al. 2002). Finco and colleagues showed that NF- $\mathrm{\kappa B}$ was a transcriptional target downstream from the Raf/mitogen-activated protein kinase (MAPK) pathway that was required to maintain the transformed phenotype of Hras ${ }^{\mathrm{G} 12 \mathrm{~V}}$-transformed cells, a finding that was later confirmed in the context of mutant Kras (Finco et al. 1997; Kim et al. 2002). Although it is well established that NF- $\kappa \mathrm{B}$ engages cell-intrinsic signaling pathways that drive cellular transformation, it is also appreciated to play a critical role in shaping the immune microenvironment 
Kras and Tumor Immunity

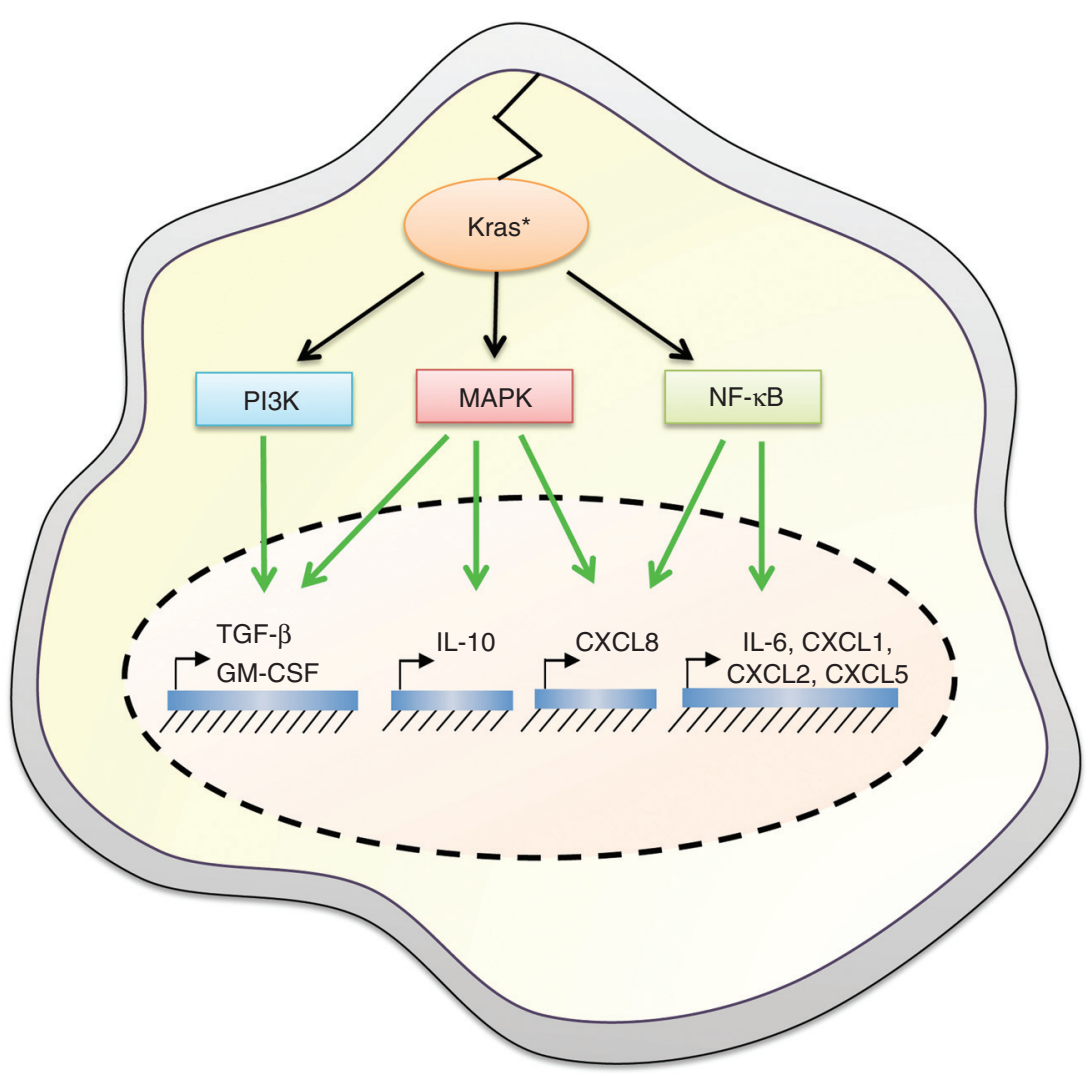

Figure 2. Secreted immunomodulatory factors transcriptionally induced by oncogenic Kras signaling. Transforming growth factor $\beta$ (TGF- $\beta$ ) and granulocyte macrophage colony-stimulating factor (GM-CSF) are regulated via the concerted action of mitogen-activated protein kinases (MAPKs) and PI3K pathways, interleukin (IL)-10 is regulated via the MAPK pathway, CXCL8 is induced by both MAPK and canonical nuclear factor (NF)$\kappa \mathrm{B}$ pathways, IL- 6 is regulated by the noncanonical RalB/TBK1/IKKE/NF- $\kappa \mathrm{B}$ pathway, and CXCL1, CXCL2, and CXCL5 are induced via the classical NF- $\mathrm{KB}$ signaling pathway.

through the transcriptional induction of a plethora of cytokines and chemokines, including tumor necrosis factor $\alpha($ TNF- $\alpha)$, IL- $1 \alpha / \beta$, IL-6, CXCL1, 2, 5, and 8, COX2, monocyte chemoattractant protein 1 (MCP-1), inducible nitric oxide synthase (iNOS), intracellular adhesion molecule 1 (ICAM1), and ELAM1 (Fig. 2) (Baud and Karin 2009). Mutant Kras can also induce the expression of cytokines via the classical Raf/MAPK and PI3K signaling pathways independently of NF- $\kappa \mathrm{B}$, such as in the case of IL-10, transforming growth factor $\beta$ (TGF- $\beta$ ), and granulocyte macrophage colonystimulating factor (GM-CSF) (Fig. 2). Below, we highlight those cytokine and growth factor families regulated directly by oncogenic Kras, the immune cells they affect, and how this modifies the tumorigenic potential of Kras-mutant tumors.

\section{ELR $^{+}$CXC Chemokines}

The ELR ${ }^{+}$CXC family of chemokines perhaps best exemplifies the expanse of mutant Krasdependent immunomodulation in human cancers, comprising CXCL1 (GRO-a/KC), CXCL2 (GRO-b/MIP2), CXCL3 (GRO-c), CXCL4, (PF4), CXCL5 (ENA-78/LIX), CXCL6 (GCP-2), CXCL7 (NAP-2), CXCL8 (IL-8), CXCL9 (MIG), CXCL10 (IP-10), CXCL11 (I-TAC), 
J. Cullis et al.

CXCL12 (stromal cell-derived factor 1 [SDF-1]), CXCL13 (BCA-1), CXCL14 (BRAK), and CXCL16. These chemokines are characterized by a canonical Cys-X-Cys (CXC) motif preceded by a Glu-Leu-Arg (ELR) sequence, which promotes their engagement with CXC receptors (CXCR1-5) that are predominantly expressed on myeloid cell types, including macrophages, neutrophils, and MDSCs (Rossi and Zlotnik 2000; Allen et al. 2007). CXCR1, also known as IL-8RA, binds to CXCL6 and 8 with high affinity, whereas CXCR2 has been shown to interact with CXCL1, 2, 3, 5, 6, 7, and 8, acting as the common mediator of their activity (Lee et al. 1992; Murphy 1994). CXCR3, in turn, preferentially binds to CXCL4, 9, 10, and 11 (Loetscher et al. 2001). O'Hayer and colleagues (2009) showed that the entire family of ELR CXC chemokines can be induced by both Hras ${ }^{\mathrm{G} 12 \mathrm{~V}}$ and Kras $^{\text {G12D }}$ in human embryonic kidney (HEK) cells. Up-regulation of all CXC chemokines was similarly observed in Kras-mutant human pancreatic cell lines (Purohit et al. 2016) and in the DMBA/TPA model of skin tumorigenesis, showing that CXC chemokine up-regulation occurs in physiologically relevant settings of Rasinduced tumorigenesis (O'Hayer et al. 2009).

\section{CXCL8}

Studies performed by Sparmann and Bar-Sagi (2004) showed that CXCL8 was transcriptionally induced by oncogenic Hras via the concerted action of AP-1 and NF- $\mathrm{\kappa B}$ transcription factors (Fig. 2). Tumors generated from $\mathrm{Hras}^{\mathrm{G} 12 \mathrm{~V}}$ transformed cells showed a robust infiltration of macrophages and granulocytes that facilitated tumor growth and whose recruitment was prevented by treating mice with a neutralizing antibody to CXCL8. Critically, they showed that the tumor cells lacked expression of CXCR1 and 2, supporting the model that CXCL8 acted cell extrinsically. Similar findings were observed in the setting of endogenous mutant Kras expression in the Kras ${ }^{\text {G12D }}$ LA1 lung adenocarcinoma (LAC) mouse model, in which lung tumorigenesis correlated with increased CXCL8 levels in the lung tissue and neutrophil recruitment (Wislez et al. 2006). Moreover, CXCR2 inhibition with a neutralizing antibody reduced the incidence and progression of lung lesions. The relevance of these studies to human disease is highlighted by the observation that CXCL8 levels are often elevated in both the serum and tumor tissues of patients with pancreatic and lung cancers (Wigmore et al. 2002; Tas et al. 2006; Frick et al. 2008). In the case of lung cancer, high CXCL8 in the serum was specifically linked to patients whose tumors harbored Kras mutations, confirming the direct relationship between Kras mutation status and CXCL8 expression in human cancer (Tas et al. 2006).

\section{CXCL1, 2, and 5}

Other ELR ${ }^{+}$CXC chemokines, CXCL1, 2, and 5 , were found to be induced by $\mathrm{Kras}^{\mathrm{G} 12 \mathrm{D}}$ in the CC10-Cre/LSL-Kras ${ }^{\text {G12D }}$ mouse model of LAC, leading to a robust infiltration of macrophages and neutrophils that was amplified with tumor progression (Ji et al. 2006). CXCL1 induction by Kras-mutant pancreatic cancer cells was required for angiogenesis and xenograft growth in studies performed by O'Hayer and colleagues (2009), as was similarly found for CXCL5 ( $\mathrm{Li}$ et al. 2011). Importantly, Steele and colleagues (2016) associated increased CXCL1, 2, and 5 expression by Kras-mutant tumor cells in situ to elevated CXCR2 signaling in the myeloid compartment of $\mathrm{Kras}{ }^{\mathrm{G} 12 \mathrm{D} /+} \mathrm{p} 53^{\mathrm{R} 172 \mathrm{H} /+}$ transgenic (KPC) mice. Global deletion of CXCR2 or depletion of neutrophils and MDSCs in these mice resulted in decreased metastasis and improved T-cell entry into the primary tumor. The therapeutic significance of these findings was shown by the sensitization of KPC mice to PD-1 checkpoint therapy when treated with a small molecule inhibitor of CXCR2. Together, these studies support an important role for mutant Kras in establishing an immunosuppressive microenvironment that affects proper cytotoxic T-cell entry and activation via the CXC-dependent recruitment of neutrophils and MDSCs. As with CXCL8, the therapeutic potential of targeting other CXC chemokines in Kras-mutant tumors is exciting given the number of studies showing the elevated expression of CXCL2 and CXCL5 in pancreatic cancers and their association with 
poorer tumor differentiation, advanced clinical stage, and/or shorter overall survival (Frick et al. 2008; Li et al. 2011; Steele et al. 2016).

\section{CYTOKINES}

A number of Kras-regulated cytokines play dominant roles in shaping the immune microenvironment. Although the signaling pathway(s) leading to the mutant Kras-dependent activation of some cytokines, such as IL-6, IL-10, TGF- $\beta$, and GM-CSF, has been delineated, such mechanistic links are lacking for many other cytokines highly expressed in Kras-mutant tumors. Below, we will focus on those cytokines that are direct transcriptional targets of oncogenic Kras.

\section{IL-6}

IL-6 is a pleiotropic inflammatory cytokine that plays an essential role in immune and cancer cell cross talk in many tumor types, primarily via the activation of the Janus kinase (JAK)/signal transducers and activators of transcription (STAT) family of transcription factors (Holmer et al. 2014). Ancrile and colleagues showed that acute induction of oncogenic Hras ${ }^{\mathrm{G} 12 \mathrm{~V}}$ resulted in IL-6 gene and protein expression in multiple cell types (Ancrile et al. 2007). Zhu and colleagues (2014b) subsequently showed that IL-6 up-regulation was mediated via noncanonical $\mathrm{NF}-\kappa \mathrm{B}$ signaling via the Kras/RalB/TBK1/ $\mathrm{IKKE} / \mathrm{NF}-\kappa \mathrm{B}$ pathway (Fig. 2). Intriguingly, McAllister and colleagues (2014) found that Kras ${ }^{\text {G12D }}$ could promote IL-17 receptor expression in preneoplastic pancreatic cells, which in turn induced IL-6 expression. These data suggest that multiple signaling pathways downstream from mutant Kras may contribute and/ or synergize to sustain high IL-6 levels. In support of these findings, in Kras-mutant pancreatic and NSCLC cell lines, IL-6 is consistently and highly up-regulated (Wigmore et al. 2002; Yamaji et al. 2004; Bellone et al. 2006; Feurino et al. 2007). A striking number of studies have found that IL-6 levels are elevated in the serum and tumor tissue of pancreatic and NSCLC patients and correlate with tumor progression, the presence of metastases, and/or poorer overall survival (Okada et al. 1998; Wenger et al. 1999; Carpagnano et al. 2002; Ebrahimi et al. 2004; Huang et al. 2005; Bellone et al. 2006; TalarWojnarowska et al. 2009; Mroczko et al. 2010; Chang et al. 2013). Despite the established negative prognostic role of IL-6 in many cancers that commonly harbor Kras mutations, relatively little is known about how tumor-derived IL-6 directly modifies the immune microenvironment. This is attributed to the fact that tumor cells can express IL- 6 receptors, allowing for the possibility that IL- 6 promotes tumor growth in a cell-autonomous manner. Moreover, IL-6 is secreted by many cell types in the tumor microenvironment, making the determination of the relative functionally active sources of IL- 6 challenging (Lesina et al. 2011; Zhang et al. 2013). Nevertheless, some studies have convincingly shown that mutant Kras-induced IL-6 secretion plays a critical role in shaping the immune microenvironment. Fukuda and colleagues showed that oncogenic Kras expression in the pancreas was required for sustained IL-6 and STAT3 signaling in the epithelial cell compartment (Fukuda et al. 2011). This was accompanied by an infiltration of myeloid cells, including MDSCs and immature myeloid cells, as well as $\mathrm{B}$ and $\mathrm{T}$ lymphocytes, whose recruitment was abrogated in STAT3-deficient Kras ${ }^{\text {G12D }}$ transgenic mice and was paralleled with an inhibition of pancreatic intraepithelial neoplasia (PanIN) formation. Although this study did not further elaborate on the functional properties of the immune cell types recruited by IL-6/STAT3 signaling, they clearly show the capacity of tumorderived IL- 6 to substantially alter the immune cell composition to one favoring tumor progression. In line with these studies, IL-6-deficient iKras ${ }^{\mathrm{G} 12 \mathrm{D}}$ mice showed decreased MDSC, macrophage, T-regulatory cell, and mast cell recruitment to the pancreas concomitant with abrogated PanIN progression (Zhang et al. 2013). Although IL-6 production was observed in Kras-mutant tumor cells in this model, it could not be causally linked to the immunosuppressive phenotype of the PanINs given their model of tissue-wide IL-6 deletion. Interestingly, in a Kras $^{\mathrm{G} 12 \mathrm{D}}$ model of lung cancer, IL-6 deletion 
J. Cullis et al.

resulted in a dramatic increase of iNOS-expressing macrophages in the lung, thereby promoting tissue damage and accelerating the onset of tumorigenesis ( $\mathrm{Qu}$ et al. 2015). These studies support the role of IL-6 in promoting an immunosuppressive microenvironment while highlighting the context specificity of the tumorigenic outcome of immunostimulatory and immunosuppressive signaling. Of note, it is also likely that IL-6-producing immune cells synergize with Kras-mutant tumor cells to amplify IL-6 levels in the tumor, as studies have shown a positive feedback loop between IL- 6 and Kras oncogenic activation (Fukuda et al. 2011).

IL-10

IL-10 is an anti-inflammatory cytokine that, like IL-6, primarily acts via the induction of the JAK/ STAT signal activation. The effect of IL-10 secretion in the tumor microenvironment has primarily been studied in the context of Treg-cell differentiation and macrophage polarization. Zdanov and colleagues (2016) showed that Kras-mutant colorectal cells transcriptionally up-regulated IL-10 via the MEK/ERK/AP-1 pathway (Fig. 2). Critically, they showed that mutant Kras-dependent IL-10 secretion was required for the conversion of $\mathrm{CD} 4^{+} \mathrm{T}$ cells to $\mathrm{CD}^{+}{ }^{+} \mathrm{FoxP}^{+}{ }^{+}$Treg cells. Moreover, Treg-cell recruitment to lung tumors was abrogated with a small molecule inhibitor of Kras activity. In PDAC and NSCLC, increased IL-10 levels have long been observed in the serum and tumor tissue of patients (Fortis et al. 1996; Hatanaka et al. 2000; von Bernstorff et al. 2001; Bellone et al. 2006), with elevated serum levels of IL-10 correlating with significantly worse survival (Hatanaka et al. 2000; Ebrahimi et al. 2004; Hsu et al. 2015). Bellone and colleagues (1999) showed that IL-10 present in pancreatic tumorcell-conditioned medium was required to abrogate peripheral blood mononuclear cell (PBMC) proliferation and Th1 cytokine production, confirming the important role of IL-10 in promoting a Th2 phenotype. In a mutant Kras-driven model of lung tumorigenesis, elevated IL-10 levels were observed in serum and tumor tissues and were required for the recruitment of M2 macrophages and Treg cells to the tumor (Hsu et al. 2015). Disruption of Treg-cell recruitment to Kras-mutant tumors has been shown to activate cytotoxic T-cell-dependent immune clearance and dramatically attenuate tumor growth in several mouse models, although in many studies the mechanistic link to tumorcell-derived IL-10 was not validated (Granville et al. 2009; Ali et al. 2014). Given the abundant IL-10 secretion in human cancers harboring Kras mutations and its established effect on Treg-cell differentiation, however, the potential of targeting IL-10 to restore immune recognition is an exciting prospect to consider.

\section{TGF- $\beta$}

TGF- $\beta$ is a pleiotropic cytokine that plays diverse cellular roles, including the regulation of cell proliferation, differentiation, migration, invasion, and survival. The development of TGF- $\beta$ knockout mice in the 1990s revealed a central role for the cytokine in the regulation of the immune system, with a particularly strong effect on the inhibition of inflammation and autoimmune diseases (Shull et al. 1992; Kulkarni and Karlsson 1993). Subsequent studies focusing on cell-type-specific deletion of TGF- $\beta$ in mice revealed a dominant role for TGF- $\beta$ in the regulation of T lymphocyte proliferation, differentiation, and survival (Gorelik and Flavell 2002), although its immunosuppressive effects also extend across B-cell, NK-cell, dendritic-cell (DC), mast-cell, and granulocyte-cell populations ( $\mathrm{Li}$ et al. 2006). TGF- $\beta$ was originally identified as a secreted protein induced by oncogenic Hras expression in breast cancer cells by Dickson and colleagues (1987). Tsubaki and colleagues (Tsubaki et al. 2011) found that inhibition of either MAPK or PI3K pathways downstream of active Ras could suppress TGF- $\beta$ induction, suggesting that both signaling axes contribute to TGF- $\beta$ production (Fig. 2). Early studies by Bellone and colleagues (1999) showed that TGF- $\beta$ was elevated in the medium of pancreatic cancer cell lines and in serum from pancreatic cancer patients. Using conditioned medium from pancreatic carcinoma cells, they found that TGF- $\beta$ contributed to the inhibition of Th1 responses 
in PBMCs, as evidenced by the reversion of these effects using TGF- $\beta$-neutralizing antibodies. Similarly, Zdanov and colleagues (2016) showed that Kras ${ }^{\mathrm{G} 12 \mathrm{~V}}$-induced Treg-cell differentiation required TGF- $\beta$ secretion from colorectal cancer cells. In this study, TGF- $\beta$ secretion was induced only in cell lines harboring mutant Kras and was mediated via the MEK/ERK/AP-1 pathway. Moreover, small molecular inhibition of Kras in mice harboring lung-specific Kras mutations prevented the infiltration of Treg cells. Perhaps the most convincing evidence for the critical role of Kras-induced TGF- $\beta$ secretion in dictating intratumoral Treg-cell differentiation was presented by Moo-Young and colleagues (2009). Adoptive transfer of $\mathrm{CD}^{+}{ }^{+}$FoxP3 ${ }^{-} \mathrm{T}$ cells into mice implanted with Kras-mutant, TGF- $\beta$-secreting tumor cells induced their differentiation into $\mathrm{CD}^{+} \mathrm{FoxP}^{+}$ Treg cells, which was reversed by systemic injection of a blocking antibody to TGF- $\beta$ or T-cellspecific inhibition of the TGF- $\beta$ receptor (MooYoung et al. 2009). Moreover, Treg-cell differentiation was not observed in mice with Kras wild-type tumors that lacked TGF- $\beta$ secretion. Intriguingly, another study showed that although global TGF- $\beta$ receptor deficiency in EL-Kras ${ }^{\text {G12D }}$ mice restored antitumor immune function, epithelial-specific deletion of TGF- $\beta$ receptor facilitated tumorigenesis, supporting the notion that tumor-cell-derived TGF- $\beta$ acts non-cell autonomously to contribute to widespread immunosuppression (Principe et al. 2016). TGF- $\beta$ levels are also elevated in NSCLC patients (Tateishi et al. 1991) and are secreted by NSCLC cells, leading to suppression of infiltrating $\mathrm{T}$-cell cytotoxic responses (Ortegel et al. 2002). In NSCLC, tumor-cell-derived TGF- $\beta$ has been further shown to suppress the activation of B cells, the maturation of DCs, and activation of NK and lymphokine-activated killer cells (Yoon 2014). These observations have led to the development of Belagenpumatucel- $\mathrm{L}$, an allogeneic tumor-cell vaccine composed of irradiated NSCLC cell lines, to block TGF- $\beta$ secretion, which is currently in phase III clinical trials (Nemunaitis et al. 2006, 2009).

Given the plethora of studies that have found elevated TGF- $\beta$ levels in the serum and tumor tissue of pancreatic and NSCLC patients (Hasegawa et al. 2001; von Bernstoff et al. 2001; Bellone et al. 2006), the role of TGF- $\beta$ in mediating immunosuppression in Kras-mutant tumors is likely of great relevance to human disease. That being said, it is not clear whether TGF- $\beta$ secreted by Kras-mutant cells constitutes the major determinant of TGF- $\beta$-dependent immunosuppression in these tumor types. Many other cell types in the tumor microenvironment are rich sources of TGF- $\beta$, including fibroblasts, pancreatic stellate cells, and immune cells themselves. Mutant Kras may indirectly promote TGF- $\beta$-mediated immunosuppression via the activation of other cell types in the tumor microenvironment, including M2 macrophages and pancreatic stellate cells, which we will touch on in our discussions of these cell types below.

\section{GM-CSF}

GM-CSF is a hematopoietic growth factor that stimulates the development of neutrophils, DCs, granulocytes, and macrophages in the bone marrow. Pylayeva-Gupta and colleagues (2012) showed Kras ${ }^{\mathrm{G} 12 \mathrm{D}}$-dependent transcriptional up-regulation of GM-CSF in pancreatic ductal epithelial cells (PDECs) that was mediated by the concerted activation of MAPK and PI3K pathways (Fig. 2). Human PDAC lesions showed selective up-regulation of GM-CSF relative to tissues from patients with other diseases of the pancreas, showing the specificity of GMCSF up-regulation in mutant Kras-induced neoplasia. Importantly, GM-CSF production by $\mathrm{Kras}^{\mathrm{G} 12 \mathrm{D}}$-expressing pancreatic tumor cells promoted the recruitment of MDSCs to the tumor microenvironment, which in turn fostered tumor growth by suppressing immune clearance by $\mathrm{CD}^{+}{ }^{+} \mathrm{T}$ cells (Bayne et al. 2012; PylayevaGupta et al. 2012). Other groups have similarly found that PDAC cell lines secrete GM-CSF, resulting in MDSC differentiation and the inhibition of T-cell proliferation (Takeuchi et al. 2015; Kenkel et al. 2017). Kenkel and colleagues found that pancreatic tumor-cell-secreted GMCSF induced DC differentiation and Treg-cell expansion at early sites of metastasis in KPC mice. Strikingly, targeted depletion of this DC 
J. Cullis et al.

population resulted in a reduction of Treg cells, activation of cytotoxic lymphocytes, and prevented metastasis formation. In line with the above findings, GM-CSF is present at high levels in pancreatic cancer patients and is correlated with reduced overall survival (Vasiliades et al. 2012; Delitto et al. 2015; Takeuchi et al. 2015). GM-CSF was also found to be elevated in NSCLC patients and to correlate with worse outcome (Baldwin et al. 1989). These data are somewhat paradoxical given that GM-CSF classically functions as an immune stimulant that in many contexts enhances antitumor immune responses. Indeed, the prognostic value of GM-CSF secretion varies widely depending on tumor type, and likely is caused by thresholds of GM-CSF levels that shift the balance from suppression to stimulation of specific immune cell types. In addition, the pleiotropic role of GMCSF may reflect the differing roles of immune activation at different stages of tumorigenesis. In the context of pancreatic cancer, however, GMCSF appears to drive immunosuppression via MDSC differentiation and cytotoxic T-cell suppression. Thus, inhibition of GM-CSF in this setting has the potential to be an effective therapeutic avenue to restore immune surveillance.

\section{KRAS' COIMMUNIST SOCIETY}

As described above, mutant Kras engages a pronounced number of immune modulating cytokines with clear and direct links to immune cell recruitment and/or differentiation. However, there are a number of cell types that play a critical role in the immune phenotype of mutant Kras tumors where the mechanistic link to Kras' oncogenic activity has not been fully elucidated. Below, we highlight some cell types that are prevalent in mutant Kras tumors and significantly impact mutant Kras-associated immunity.

\section{Macrophages}

Macrophage infiltration occurs early in NSCLC and PDAC tumorigenesis and is an established promoter of tumor progression. Depending on signals that prevail within their microenvironment, macrophages can adopt a variety of func- tional states. In response to bacterial products such as lipopolysaccharide (LPS) and Th1 cytokines, macrophages become immunostimulatory (M1). M1 macrophages are characterized by the expression of high levels of iNOS, major histocompatibility complex II (MHCII), cluster of differentiation 80 and 86 (CD80, CD86), TNF- $\alpha$, contributing to their tumoricidal effect (Mantovani et al. 2002). In contrast, in the presence of Th2 cytokine macrophages acquire an alternatively activated state (M2) that is immunosuppressive, tumor promoting, and is characterized by the expression of arginase 1, cluster of differentiation 206 (CD206), and low levels of MHCII. In pancreatic cancer, tumor-associated macrophages (TAMs) show both M1 and M2 phenotypes, although higher M2:M1 ratios correlate with disease progression, metastasis, and shorter survival in patients (Kurahara et al. 2011; Ino et al. 2013). Other studies have argued that both M1 and M2 macrophages are tumor promoting but play distinct roles in the initiation (M1) and progression (M2) of tumorigenesis (Liou et al. 2015). Although cytokines discussed previously in this review such as IL-10 and TGF- $\beta$ can drive M2 phenotypes, a direct link between mutant Kras-induced secretion of these cytokines and macrophage polarization in PDAC has not been stringently tested. Interestingly, Liou and Storz (2015) showed that $\mathrm{Kras}^{\mathrm{G} 12 \mathrm{D}}$ expression in pancreatic acinar cells drove the expression of ICAM1, which served as a chemoattractant for M1 macrophages. Although the precise mechanism of ICAM1-dependent macrophage recruitment was not investigated, the authors speculated that proteases secreted by acinar cells processed ICAM1 into a soluble form that could bind to unidentified receptors present on macrophages. Liou and colleagues (2013; Liou and Storz 2015) further show that ICAM1-dependent macrophage recruitment promoted acinar-to-ductal metaplasia (ADM) via TNF- $\alpha$ and CCL5 production, thereby contributing to neoplastic transformation and providing functional evidence of a temporally dependent, tumor-promoting role of M1 macrophages in early pancreatic tumorigenesis. In advanced stages of pancreatic tumorigenesis, macrophages play a 
primarily immunosuppressive role and emerge as one of the most abundant immune cell types present in the tumor microenvironment (Mielgo et al. 2013). M2 macrophages have been shown to contribute to angiogenesis, invasion (via MIP-3 $\alpha$ ), metastasis (via vascular endothelial growth factor [VEGF]), and the promotion of cancer stem-cell-like properties (via aldehyde dehydrogenase $[\mathrm{ADLH}])$. Zhu and colleagues (2014a), in turn, showed that CSF1 was produced by human PDAC cells and that CSF1 receptor blockade in an orthotopic model of PDAC abrogated the infiltration of M2 macrophages, with modest increases in cytotoxic Tcell activation.

In NSCLC, macrophages constitute a dominant immune cell type whose correlation with patient prognosis remains controversial (Dai et al. 2010; Remark et al. 2015; Busch et al. 2016). For example, Chen and colleagues found that TAMs were associated with negative prognosis in NSCLC patients, whereas Toomey and colleagues found no association between the presence of TAMs and overall survival (Chen et al. 2003; Toomey et al. 2003). In contrast, Dai and colleagues (2010) discovered that TAMs in the stroma correlated with worse survival, whereas TAMs in the tumor islets predicted better overall survival of NSCLC patients. In the CCSP-Kras ${ }^{\mathrm{G} 12 \mathrm{D}}$ murine model of lung cancer, Redente and colleagues (2010) showed that macrophages in and surrounding lung tumors showed an M2 phenotype early in tumor progression that was reversed to an unpolarized state on extinction of the mutant Kras transgene expression. Intriguingly, comparison of the immune profile of epidermal growth factor receptor (EGFR), Kras ${ }^{\mathrm{G} 12 \mathrm{D}}$, and $\mathrm{Kras}^{\mathrm{G} 12 \mathrm{D} /+} \mathrm{p} 53^{\mathrm{R} 172 \mathrm{H} /+}$ transgenic mice revealed that macrophage numbers increased over time specifically in the background of an oncogenic Kras allele, supporting the notion that mutant Kras is sufficient to direct macrophage infiltration (Busch et al. 2016). Although the precise mechanism of macrophage recruitment to mutant Kras-driven lung tumors has not been established, several groups have found that macrophage CXCR2 signaling was required for TAM recruitment in both transgenic and hu- man xenograft models of Kras-mutant lung cancer, suggesting that the mutant Kras-dependent secretion of ELR-CXC chemokines may constitute one mechanism of macrophage attraction (Cortez-Retamozo et al. 2012; Schmall et al. 2015).

\section{B Cells}

Only recently has the significance of tumor-infiltrating B cells in Kras-mutant tumors been unveiled, although it has been largely restricted to studies performed in pancreatic cancer models. B cells constitute a significant proportion of lymphocytes in both early and late stages of pancreatic cancer (Gunderson et al. 2016; Pylayeva-Gupta et al. 2016), with a somewhat contradictory role in tumorigenesis. Although pan-B-cell numbers correlated with improved disease prognosis, elevated levels of B-cell-activating factors in tumors correlated with increased metastatic potential (Koizumi et al. 2013; Tewari et al. 2013). However, subsequent studies by three independent groups using distinct oncogenic Kras-driven mouse models showed a protumorigenic role for tumor-infiltrating B cells (Gunderson et al. 2016; Lee et al. 2016; Pylayeva-Gupta et al. 2016). Interestingly, the tumor-promoting functions of the B-cell population were mediated through distinct Bcell subpopulations at different stages of disease progression. Pylayeva-Gupta and colleagues (2016) identified a subset of regulatory B cells that promoted PanIN initiation and early progression through the secretion of IL-35. In parallel to these findings, Gunderson and colleagues (2016) identified a population of antibody-producing B cells that promoted macrophage M2 polarization and tumor growth in advanced PDAC. Furthermore, a tumor-protective role was attributed to the B1 $\beta$ subset of $B$ lymphocytes in early pancreatic neoplasms by Lee and colleagues (2016). Collectively, these studies provide evidence that the role of $\mathrm{B}$ cells in promoting pancreatic cancer is complex and highly contextual. Although the importance of $\mathrm{B}$ cells in lung cancer is limited, regulatory B cells were found to be elevated in lung cancer patients (Zhou et al. 2014). In addition, Busch and 
J. Cullis et al.

colleagues (2016) observed a substantial recruitment of $\mathrm{B}$ cells in early and late stages of tumor progression in the CCSP-Kras ${ }^{\mathrm{G} 12 \mathrm{D}}$, but not CCSP-EGFR ${ }^{\mathrm{L} 858 \mathrm{R}}$ transgenic LAC mouse model, providing further support that cells expressing mutant Kras secretes B-cell-attracting factors in multiple contexts. Ultimately, although these studies elucidate an important role for B cells in oncogenic Kras-driven tumors, the mechanism of B-cell recruitment remains an area of active research. In our own study, we have identified the role of fibroblast-derived chemoattractant CXCL13 in promoting B-cell infiltration in pancreatic neoplasia, although the connection to oncogenic Kras remains elusive and merits further investigation (PylayevaGupta et al. 2016).

\section{Th17 Cells}

Th17 cells are a recently discovered lineage of Th cells that are potent immunostimulators through the production of the cytokine IL17A. Murine models of Kras-mutant lung and pancreatic tumorigenesis showed a significant enrichment in Th17 cells (Chang et al. 2014; McAllister et al. 2014; Marshall et al. 2016). Similar findings were reported by Zhang and colleagues (2014) in the iKras ${ }^{\mathrm{G} 12 \mathrm{D}}$ model of pancreatic cancer, although in this case the induction of pancreatitis was required to detect Th17 cells in the tumor microenvironment. Furthermore, infiltration of Th17 cells and high plasma IL-17A levels correlated with poor prognosis in NSCLC and pancreatic cancer patients (McAllister et al. 2014; Duan et al. 2015; Marshall et al. 2016). Importantly, Busch and colleagues (2016) showed that Th17 cells were specifically recruited in mutant Kras transgenic mice compared to mutant EGFR-transgenic mice in lung cancer models. Although the mechanistic link between mutant Kras and Th17-cell recruitment and/or differentiation has not been specifically addressed, IL- 6 and TGF- $\beta$, transcriptional targets of mutant Kras described in previous sections, are potent inducers of Th17 differentiation. Given that these cytokines are also produced by several additional tumor-associated cell types, including fibro- blasts and immune cells (Löhr et al. 2001; Lesina et al. 2011), the recruitment of Th17 cells is likely facilitated by multiple cell types in the tumor microenvironment. In addition, in pancreatic cancer, mutant Kras-dependent up-regulation of the IL-17 receptor on tumor cells may also promote their interaction with Th17 cells (McAllister et al.2014). Functionally, ablation of Th17 cells in oncogenic Kras models of lung and pancreatic cancer significantly abrogated tumor initiation and progression, with loss of IL-17A resulting in reduced tumor-cell proliferation, angiogenesis, and MDSC recruitment (Chang et al. 2014; McAllister et al. 2014). Zhang and colleagues (2014) further showed that genetic depletion of $\mathrm{CD}^{+}{ }^{+} \mathrm{T}$ cells, including the Th17 population, resulted in the derepression of stromal $\mathrm{CD}^{+}{ }^{+}$cytotoxic $\mathrm{T}$ cells and subsequent attenuation of tumor progression. Collectively, these data point to an important role for Th17 cells in mediating immunosuppression in Krasmutant tumors and warrants a more thorough investigation of the mechanism of Th17 recruitment to the tumor microenvironment.

\section{$\gamma \delta$ T Cells}

An additional source of IL-17 in the Kras-mutant tumor microenvironment is derived from $\gamma \delta \mathrm{T}$ cells, a distinct subclass of T cells that are characterized by the expression of the $\gamma \delta$ T-cell receptor (TCR). $\gamma \delta$ T cells constitute up to threequarters of tumor-infiltrating $\mathrm{T}$ cells in human PDAC samples. Interestingly, however, Daley and colleagues (2016) described a tumor-protective role for $\gamma \delta \mathrm{T}$ cells in pancreatic cancer. Genetic depletion of $\gamma \delta$ T cells in KC mice severely decreased ADM and subsequent PanIN progression and was accompanied by increased Th1 response and elevated cytotoxic T-cell activity. Surprisingly, deletion of $\gamma \delta \mathrm{T}$ cells in Kras-mutant LAC did not impact tumor burden, emphasizing the complexity of differential immune modulation depending on the tumor type (Busch et al. 2016). In the Daley and colleagues' (2016) study, $\gamma \delta$ T-cell recruitment to the tumor was contingent on ligation of the CC chemokine receptor family members CCR2, CCR5, and CCR6, leading to the tempting spec- 
ulation that mutant Kras may contribute to CC chemokine production (Daley et al. 2016). In line with the surprising tumor-protective role of abundantly expressed $\gamma \delta \mathrm{T}$ cells in pancreatic cancer, the functional significance of this cell population in mutant Kras-driven tumor progression remains controversial. This may be because of the selective recruitment of two distinct $\gamma \delta$ T-cell subpopulations in different tumors: the antitumorigenic interferon (IFN) $-\gamma^{+} \mathrm{CD} 27^{+}$ $\gamma \delta \mathrm{T}$ cells and the protumorigenic IL-17A ${ }^{+}$ $\mathrm{CD} 27^{-} \gamma \delta \mathrm{T}$ cells. Undoubtedly, further investigation is needed to untangle the specific and context-dependent roles of this T-cell population in Kras-mutant tumors, as well as their mechanism of recruitment to the tumor microenvironment.

\section{Stellate Cells}

A principal theme reinforced throughout the previous sections has been that the functional output of mutant Kras-induced immune signaling pathways is modified by tumor-cell interactions with neighboring cells and cytokines in their microenvironment. With this theme in mind, it is critical that we not only consider the immune cells directly stimulated by mutant Kras signaling, but other cell types that are regulated by Kras-mutant cells that may also modulate immune cell recruitment. This concept is best explored in PDAC because of its extensive stromal compartment composed of fibroblasts, pancreatic stellate cells (PSCs), extracellular matrix (ECM) proteins, endothelial cells, nerve cells, and adipocytes in addition to immune cells. PSCs are the most prevalent cell type in the pancreatic tumor stroma and are established contributors to disease progression (Omary et al. 2007). PSCs are myofibroblast-like cells that are normally present in a quiescent state in areas of the exocrine pancreas. In chronic pancreatitis and the early stages of pancreatic cancer, PSCs become activated (aPSCs), inducing their proliferation, migration, and secretion of ECM components and promotion of wound repair. Importantly, PSCs are activated in response to factors produced by Kras-mutant tumor cells, and in turn secrete cytokines that direct immune-cell recruitment. A major factor in the pancreatic tumor microenvironment (TME) responsible for the activation of PSCs is tumor-cell-derived TGF- $\beta$, which induces the proliferation and secretion of type I collagen and fibronectin in fibroblasts (Fig. 3) (Löhr et al. 2001). A number of other growth factors, including fibroblast growth factor (FGF), heparin-binding epidermal growth factor (HB-EGF), platelet-derived growth factor (PDGF), and sonic hedgehog (SHH) are also secreted by Kras-mutant PDAC cells and contribute to PSC activation (Means et al. 2003; Kordes et al. 2005; Bailey et al. 2008; Tian et al. 2012). In turn, aPSCs produce a plethora of chemokines, cytokines, and growth factors, including several ELR ${ }^{+}$CXC chemokines, TGF- $\beta$, TNF- $\alpha$, connective tissue growth factor (CTGF), MCP1 , regulated and normal T-cell regulated and secrete (RANTES), SDF-1, and IL- $1 \beta, 4,6,8$, 13, and 15 (Andoh et al. 2000; Apte et al. 2012; Mace et al. 2013a,b; Xue et al. 2015). Given the expanse of the aPSC immunomodulatory secretome and the significant overlap with factors induced by mutant Kras, it comes as no surprise that aPSCs strongly amplify the immune phenotype of PDAC.

The cytokine profile of aPSCs offers a pertinent example of how parallel secretion of immunosuppressive factors by stellate cells and Kras-mutant cells can amplify immune cell recruitment to the tumor. For example, isolation of a mesenchymal stem cell (MSC) subtype of stellate cells from KC mice revealed the increased expression of macrophage colonystimulating factor (M-CSF) and GM-CSF, in addition to IL-6, IL-10, and TGF- $\beta$, relative to wild-type mice (Fig. 3) (Mathew et al. 2016; Waghray et al. 2016). Coinjection of KC-derived MSCs with tumor cells induced a significant increase in macrophage number in the tumor and promoted their polarization to an M2 phenotype via elevated IL-6 and IL-10 secretion (Mathew et al. 2016). Critically, macrophage recruitment by the MSCs was required for the increase in tumor size observed following coimplantation of MSC and $\mathrm{Kras}^{\mathrm{G} 12 \mathrm{D} / \mathrm{H}} \mathrm{p} 53^{\mathrm{R} 172 \mathrm{H} /+}$ cells. These findings were paralleled in an orthotopic model of human PDAC, in which coinjec- 
J. Cullis et al.

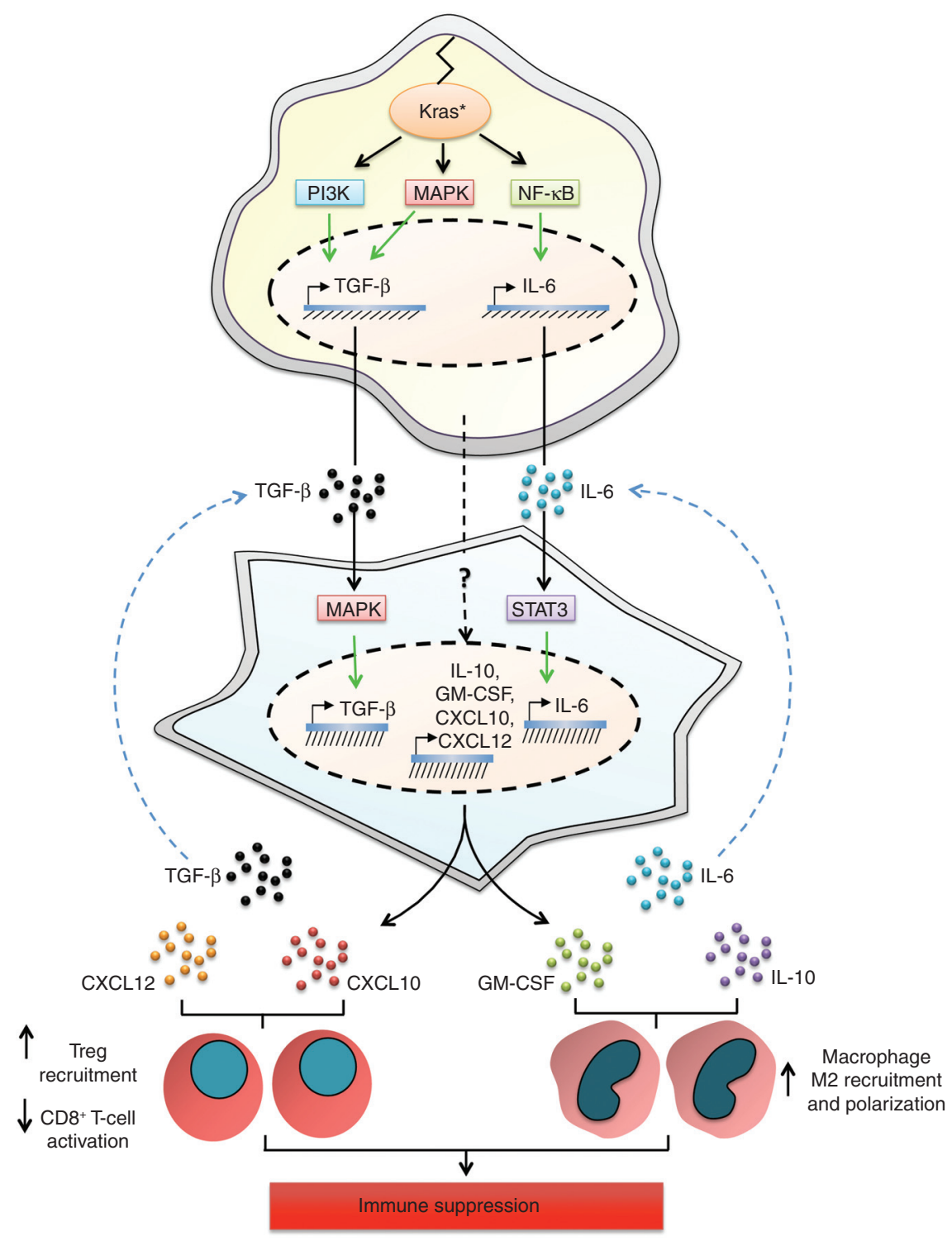

Figure 3. Cooperation of Kras-mutant tumor cells with pancreatic stellate cells in tumor microenvironment (TME) immunomodulation. Kras-mutant tumor-cell-derived transforming growth factor $\beta$ (TGF- $\beta$ ) induces the activation of pancreatic stellate cells (PSCs) in the pancreatic TME, resulting in mitogen-activated protein kinase (MAPK) pathway activation and induction of TGF- $\beta$ transcription and secretion by PSCs. Increased TGF- $\beta$ levels can both promote $\mathrm{T}$ regulatory (Treg) recruitment and macrophage M2 polarization, thereby contributing to immunosuppression in the TME. Similarly, interleukin (IL)-6 produced by Kras-mutant tumor cells binds to IL6 receptors on PSCs, resulting in intracellular signal transducers and activators of transcription 3 (STAT3) activation and IL-6 transcription and secretion into the TME. High IL-6 levels amplify the recruitment and M2 polarization of macrophages, thereby promoting tumor growth. Although the mechanism of transcriptional induction of IL-10, granulocyte macrophage colony-stimulating factor (GM-CSF), CXCL10, and CXCL12 by PSCs has not been directly addressed, their secretion by PSCs cooperates with IL-10, GM-CSF, CXCL10, and CXCL12 derived from Kras-mutant tumor cells to amplify Treg cell recruitment (CXCL10), dampen CD8 ${ }^{+}$T-cell responses (CXCL12), or promote macrophage M2 polarization (IL-10, GM-CSF) in the pancreatic TME. NF- $\mathrm{BB}$, Nuclear factor $\kappa B$. 
tion of tumor cells with tumor-derived MSCs harboring stable GM-CSF knockdown resulted in a reduction in number and proportion of M2 macrophages in the tumor (Waghray et al. 2016). By contrast, Xue and colleagues found that aPSC-induced M2 macrophage polarization was dependent on IL-4 and IL-13 secretion in an experimental model of chronic pancreatitis, suggesting that increased levels of cytokines derived from both Kras-mutant cells and aPSCs may alter the cytokine dependence for M2 polarization to one favoring IL-6 and IL-10 (Xue et al. 2015). aPSCs were also reported to promote the differentiation of PBMCs to CD11b-expressing MDSCs via IL-6 production, which resulted in the inhibition of T-cell proliferation (Mace et al. 2013a,b).

The profoundly dampened cytotoxic T-cell responses observed in PDAC may also be attributed to synergistic effects of aPSCs and Krasmutant tumor cells, but likely mediated through their concomitant secretion of CXC chemokines. Indeed, many reports have established that aPSCs can inhibit CD8 ${ }^{+} \mathrm{T}$-cell recruitment and activation (Watt and Kocher 2013). EneObong and colleagues (2013) showed that aPSCs sequestered $\mathrm{CD} 8^{+} \mathrm{T}$ cells and prevented their infiltration around tumor cells, resulting in reduced antitumor immunity. Similarly, fibroblast activation protein-positive aPSCs $\left(\mathrm{FAP}^{+}\right.$ aPSCs), an additional subtype of aPSCs, were reported to disrupt antitumor immunity via the repulsion of $\mathrm{T}$ cells from tumor cells via CXCL12 production in KPC mice (Feig et al. 2013). Intriguingly, although $\mathrm{FAP}^{+}$aPSCs were deemed the principal source of CXCL12, tumor cells also colocalized with the chemokine, suggesting that both tumor-cell- and aPSC-derived CXCL12 may cooperate to regulate T-cell responses (Fig. 3). Critically, on small molecule inhibition of the CXCL12 receptor, T-cell accumulation was restored and the checkpoint agonist PD-L1 was effective in inducing tumor regression. Lunardi and colleagues, in turn, found that human PDAC cells induced CXCL10 expression in aPSCs, which induced the recruitment of $\mathrm{CXCR}^{+}$effector $\mathrm{T}$ cells and Treg cells and correlated with their presence in human PDAC samples (Fig. 3) (Lunardi et al.
2014). These data highlight the interdependence of chemokine secretion between aPSCs and PDAC cells and strongly argue in favor of the concept that mutant Kras synergizes with aPSCs to dictate the immune phenotype of PDAC.

In addition to the plethora of cytokines and chemokines that are common to aPSCs and Kras-mutant tumor cells, aPSCs secrete a number of unique factors that independently contribute to the immune contexture of PDAC. For example, galectin 1 was found to be a principal mediator of T-cell suppression in PanINs and PDAC and is uniquely expressed by aPSCs (Tang et al. 2012, 2015). Zambirinis and colleagues (2015) showed that CCL3 secretion by aPSCs was required for the recruitment of Treg cells in KPC mice. Ultimately, the immune effects of aPSCs are dictated by mutant Kras on multiple levels, starting with the initial requirement of oncogenic Kras-induced factors for their activation, and followed by their synergistic and distinct cytokine and chemokine profiles that together help shape the immune phenotype of PDAC.

\section{MUTANT KRAS-DEPENDENT IMMUNE MODULATION: CONTEXT MATTERS}

\section{Inflammation: Making the Most of It}

The potent effects of mutant Kras on the immunogenicity of the tumor microenvironment brings to question how it may cooperate with or regulate external inflammatory insults associated with tumor development. Kras is most frequently mutated in PDAC (95\%), NSCLC (35\%), and colorectal cancer (CRC) (40\%) tumor types that are highly associated with the inflammatory disorders pancreatitis, chronic obstructive pulmonary disorder (COPD) and smoking, and ulcerative colitis (UC), respectively (Lowenfels et al. 1993; Ahrendt et al. 2001; Malka et al. 2002; Young et al. 2009; Jess et al. 2012). Below, we describe how mutant Kras' immunomodulatory outputs interact with pancreatitis and COPD to modulate the development of PDAC and NSCLC. 
J. Cullis et al.

Using pancreatic acinar-cell-specific expression of mutant Kras, Guerra and colleagues (2011) described a highly refractory mouse model of PanIN that acquired tumorigenic properties following the induction of chronic pancreatitis. Mutation of Kras concomitant with loss of tumor suppressors, such as Trp53 or p16Ink4a/p19Arf, and caerulein-induced pancreatitis resulted in malignant PDAC disease. The authors proposed that pancreatitis contributed to PanIN progression through the induction of its own inflammatory signature, abrogating oncogenic Kras-induced senescence in mutant precursor cells and delaying tissue repair, thereby providing the mouse PanINs with the potential to expand and progress. Further mechanistic insight into the synergistic effects of pancreatitis and mutant Kras was provided by Fukuda and colleagues, who showed that the transient expression of IL- 6 and activation of STAT3 signaling induced by acute pancreatitis was amplified and prolonged in the presence of a mutated Kras allele (Fukuda et al. 2011). This was also observed by McAllister and colleagues (2014), who further discovered that IL-17A levels and the recruitment of Th17 and IL- $17^{+} / \gamma \delta$ T cells were synergistically increased by Kras ${ }^{\text {G12D }}$ and pancreatitis.

Similar observations were made in an LSL$\mathrm{Kras}^{\mathrm{G} 12 \mathrm{D}} / \mathrm{CCSP}^{\mathrm{Cre}}$ model of lung cancer, wherein Haemophilus influenzae infection-mediated induction of COPD resulted in increased lung tumor burden, accompanied by a robust infiltration of myeloid cells (Moghaddam et al. 2009). Consistent with the pancreatitis studies, oncogenic Kras cooperation with COPD in lung cancer was also determined to be a consequence of amplified Th17 recruitment, relative to mutant Kras alone, leading to enhanced IL-17 production and MDSC infiltration (Chang et al. 2014) and resulting in an increase in tumor burden and disease progression. Together, these studies indicate that exogenous inflammatory conditions amplify Kras' immunodulatory effects to further promote oncogenic transformation.

The significance of mutant Kras' cooperation with additional inflammatory diseases in tumorigenesis is emphasized by the observation that oncogenic mutations in Kras have been de- tected in disease-free pancreas of healthy individuals (Terhune et al. 1998; Lüttges et al. 1999; Löhr et al. 2005). Furthermore, the reciprocity of this relationship is evident by the lack of oncogenic transformation observed in wild-type mice subjected to induction of pancreatitis or COPD. Hence, although oncogenic mutation of Kras or inflammation of the pancreas and the lung individually create a strong predisposition for transformation, synchronously they create an optimal immune microenvironment that accelerates tumor progression.

\section{Different Folks for Different Strokes}

As described previously, a significant proportion of mutant Kras-mediated immune modulation mechanisms are a function of its paracrine signaling to components of the tumor microenvironment. The inherent tissue-specific variations of the tumor stroma thus profoundly impact the immunological characteristics of different mutant Kras-expressing tumor types, which can in turn have significant implications for disease progression and therapeutic intervention. This is perhaps best exemplified by the variations observed in the $\mathrm{CD}^{+}$Tc cell compartment of Kras ${ }^{\mathrm{G} 12 \mathrm{D}}$-bearing PDAC and NSCLC tumors.

Extensive characterization of $\mathrm{Kras}^{\mathrm{G} 12 \mathrm{D}}$. driven PDACs, both in mouse models and human samples, has revealed the PDAC TME to be largely immunosuppressive, with high levels of myeloid cell infiltration, especially the M2 polarized TAMs and MDSCs (Mantovani et al. 2006; Clark et al. 2009; Markowitz et al. 2015). MDSC infiltration in the PanIN and PDAC microenvironment strongly correlates with paucity of infiltrating $\mathrm{T}$ cells, more specifically the tumoricidal CD8 ${ }^{+}$Tc cells (Ino et al. 2013; Vonderheide and Bayne 2013). Furthermore, the few $\mathrm{CD}^{+} \mathrm{T}$ cells that are present exist in a state of clonal anergy with an absence of markers of activation.

In remarkable contrast to this, the TME of $\mathrm{Kras}^{\mathrm{G} 12 \mathrm{D}}$ lung cancer mouse models, although also rich in macrophages and MDSCs, display significant expansion of $\mathrm{CD}^{+}{ }^{+} \mathrm{Tc}$ cells (Busch et al. 2016). This observation is also corroborated in human NSCLC samples in which mu- 
tant Kras tumors associate with higher $\mathrm{CD}^{+} \mathrm{T}$ cell infiltration in the stroma.

Mechanistically, the scarcity of tumor-infiltrating $\mathrm{CD}^{+} \mathrm{T}$ cells in $\mathrm{Kras}^{\mathrm{G} 12 \mathrm{D}}$-driven PDAC has been attributed to the unique architecture of the PDAC stroma, characterized by intense desmoplasia, fibrosis, and presence of mutant Ras-activated PSCs. Early on, von Bernstorff and colleagues (2001) argued that tumor-infiltrating lymphocytes (TILs) become "trapped" within the peritumoral, fibrous stroma, thereby preventing them from reaching their malignant cellular targets. Ene-Obong and colleagues (2013) elaborated on these findings using the KPC PDAC mouse model and showed that $\mathrm{Kras}^{\mathrm{G} 12 \mathrm{D}}$-induced aPSCs inhibited juxtatumoral $\mathrm{CD}^{+} \mathrm{T}$-cell infiltration through the expression of cytokines, chemokines, and adhesion molecules that regulate T-cell migration.

The difference in $\mathrm{CD} 8^{+} \mathrm{T}$-cell infiltration in PDAC versus NSCLC significantly impacts the design of therapeutic strategies for the two diseases. Owing to the lack of infiltrating $\mathrm{CD} 8^{+} \mathrm{Tc}$ cells, PDAC has proved to be a poor candidate for immune checkpoint monotherapy (Sharma et al. 2015; Topalian et al. 2015). Conversely, $\mathrm{CD}^{+} \mathrm{Tc}$ infiltration in $\mathrm{Kras}^{\mathrm{G} 12 \mathrm{D}}$-driven lung cancer has prompted the exploration of checkpoint inhibitors as a viable therapeutic means. Consequently, the co-occurrence of Kras and p53 mutations in NSCLC is emerging as a predictive biomarker for immune checkpoint therapy, with those patients harboring both mutations showing significantly longer progression-free survival on PD-1 blockade therapy (Ji et al. 2006; Herter-Sprie et al. 2016; Dong et al. 2017).

In light of these outcomes, continued comparative analysis of oncogenic Kras' molecular and cellular modes of action in different tumor types is clearly imperative for understanding and devising organ-specific therapeutic strategies.

\section{IS KRAS IMMUNE?}

\section{An Inflamed Achilles Heel}

The disappointing outcome of the attempts to directly target oncogenic Ras (Cox et al. 2014) has generated an urgent need to develop alternative therapeutic strategies to treat mutant Rasdriven cancers. An alternative approach consists of disrupting the biological outputs influenced by oncogenic Ras in lieu of its specific molecular functions. The current chemotherapeutic treatment for pancreatic and lung cancer consists of cytotoxic drugs like gemcitabine and paclitaxel, which primarily target the high proliferative index of cancer cells and are not specific to the unique properties of Kras-mutant tumor cells. Of note, we have recently discovered an immunostimulatory effect of nab-paclitaxel on macrophages in PDAC that may prove useful in combination therapies with other immunomodulatory agents (Cullis et al. 2017). However, a single regimen with either drug so far provides only modest benefits, especially in advanced stages, because of a high degree of acquired or inherent resistance. Combinational therapy-targeting multiple facets of the tumor are therefore a need of the day.

Given the significant role of immunosuppression in promoting growth of Ras-mutant tumors, immunotherapy is an attractive therapeutic approach. Immunotherapy uses strategies aimed at activating an antitumor immune response, predominantly mediated through $\mathrm{CD}^{+}$cytotoxic $\mathrm{T}$ cells, in addition to NK cells and macrophages with tumoricidal activity (Stambrook et al. 2017). These strategies can either be aimed directly at the $\mathrm{CD} 8^{+} \mathrm{Tc}$ cells or indirectly lead to their activation by inhibiting the immunosuppressive cells and factors in the TME. Here, we discuss the promising potential of targeting the mutant Ras-induced immunomodulation mechanisms as a means to release the breaks on the host tumoricidal immune responses and thereby combat oncogenic Ras-driven cancers. Furthermore, we briefly describe the recent advances made in harnessing the power of the host immune system to target mutant Ras itself.

\section{Setting Our Cytokines High}

As previously described, oncogenic Ras-dependent processes that modulate the protumorigenic immune composition of the TME in- 
J. Cullis et al.

cludes the secretion of a considerable number of cytokines and chemokines including CSF-1, IL-6, and CCL2 (Fukuda et al. 2011; Agalioti et al. 2017). Immunotherapeutic strategies aimed at neutralizing these secreted factors or blocking their cognate receptors may therefore be an efficient strategy in combinational therapies. As a proof of principle, Mace and colleagues showed antitumor activity of a combined PD-L1 and IL-6 blockade regimen in orthotopically transplanted Panc02 PDAC cells that also resulted in the induction of tumor regression and increased survival in KPCBRCA2 mice (Mace et al. 2016). Similar results were obtained in a mouse model of mutant Kras-driven lung cancer on monotherapy with an IL-6-neutralizing antibody (Caetano et al. 2016). IL-6 inhibition in CCSP-Kras ${ }^{\text {G12D }}$ mice resulted in decreased M2 macrophages and MDSC levels in the TME and a skewing of the T-cell protumor Th17/Treg response to the antitumor Th1/CD8 ${ }^{+} \mathrm{Tc}$ response, resulting in tumor regression.

Along similar lines, individual administration of small molecule inhibitors of CCR2 and CSF1R tyrosine kinase in Kras ${ }^{\mathrm{G} 12 \mathrm{D}}$ orthotopic PDAC mice resulted in a significant reduction in tumor-infiltrating macrophages and monocytes (Mitchem et al. 2013). Furthermore, administration of either inhibitor with gemcitabine dramatically reduced tumor progression of both Pan02 and Kras ${ }^{\mathrm{G} 12 \mathrm{D}}$-INK orthotopic transplants. Following up on these promising results, the CCR2 inhibitor PF-04136309 in combination with the chemotherapeutic regimen FOLFIRINOX is currently in clinical trials, with phase $1 \mathrm{~b}$ results revealing $52 \%$ partial response and $47.8 \%$ of patients showing stable disease (Wang-Gillam et al. 2016). CXCR2 has also recently been shown as a potential effective target for combination therapy in PDAC. Pharmacological ablation of CXCR2 signaling in a preclinical PDAC mouse model not only abrogated metastasis but also enhanced T-cell infiltration, thereby sensitizing the tumor to anti-PD-1 checkpoint therapy and extending survival in combination therapy (Steele et al. 2016). Whereas these results are very encouraging, more extensive investigations in larger trials are needed for further evaluation and development.

\section{A New Way to Target Mutant Kras?}

Although the primary objective of this article is to provide an overview of oncogenic Kras-mediated immune modulation in cancer and its implications on disease progression and therapeutic targeting, we would be remiss to not discuss the potential of mutant Kras itself as a target for emerging immunotherapeutic strategies that are showing great promise.

Oncogenic mutation of Kras can generate neoantigenic peptides with the potential to generate a cytotoxic T lymphocyte (CTL) response against the mutated tumor cells. Activated $\mathrm{CD} 8^{+}$ Tc cells express TCRs, which specifically recognize these neoantigens. They are typically 8 - to 11-amino-acid-long mutated Ras peptides presented in complex with host-specific MHC class I molecules by antigen-presenting cells (APCs) or tumor cells (Maher and Davies 2004). Mutant Ras epitopes are attractive targets for CTL-based response because Ras mutations occur early in tumorigenesis and are inherited in almost all cells within a heterogeneous tumor. Although the overall levels of tumor-reactive CTLs in oncogenic Ras-driven tumors is low, multiple studies conducted earlier have detected the presence of such autoreactive $\mathrm{CD} 8^{+} \mathrm{Tc}$ populations in CRC, PDAC, melanoma, and lung cancer patients (Fossum et al. 1995; Linard et al. 2002; Trojan et al. 2003; Kubuschok et al. 2006). These observations have recently led to the first-ever successful targeting of metastatic lesions in a CRC patient by adoptive transfer of CTLs specifically against the mutant Kras ${ }^{\text {G12D }}$ isoform (Rosenberg et al. 2017). TIL cultures isolated from surgically resected secondary tumors in the lung containing active $\mathrm{CD}^{+} \mathrm{Tc}$ cells against the $\mathrm{Kras}^{\mathrm{G} 12 \mathrm{D}}$ neoantigen were identified, expanded, and transplanted back into the patient. Remarkably, all metastatic lung lesions underwent regression postadoptive transfer and the treatment had no adverse side effects. In the absence of direct mutant Kras inhibitors, the development of such alternative methods to target oncogenic Ras directly is an 
incredibly exciting prospect to pursue (Baines et al. 2011).

\section{FUTURE PERSPECTIVES}

In this review, we describe the emerging role of mutant Ras in shaping the immune microenvironment. This occurs through mutant Rasdependent transcriptional induction of chemokines, cytokines, and growth factors that recruit and functionally regulate cells of both the innate and adaptive immune system. Although many of the pathways linking mutant Ras to immune modulation have been delineated, much remains unknown about how these pathways interact combinatorially and how their output is modulated by tissue and organ context. Furthermore, although significant progress has been made on broadly defining the immune composition of the tumor microenvironment, several challenges impede a detailed molecular understanding of the interactions between tumor and immune cells. These include a scarcity of model systems that faithfully recapitulate the immune characteristics of human tumors and barriers to accessing the full complement of immune-cell subpopulations within tumors. The development of tumor mouse models with genetically humanized immune systems and the rapid advancement of imaging and sequencing techniques that enable the interrogation of immune cells at the single-cell levels offer promising prospects for deeper characterization of the cross talk between mutant Ras cancers and immune cells in the tumor microenvironment. This knowledge will undoubtedly enhance our understanding of how to harness the immune system for the treatment of mutant Ras tumors.

\section{ACKNOWLEDGMENTS}

The authors thank L.J. Taylor for help with figure preparation. This work is supported by funding from National Institutes of Health (NIH)/National Cancer Institute Grant CA 210263, American Association for Cancer Research (AACR) PanCAN Grant 13-90-25VOND, a Project Purple grant, and Stand Up To Cancer-The Lustgarten Foundation Pan- creatic Cancer Convergence Dream Team Grant SU2C-AACR-DT14-14 (to D.B.-S.). Stand Up To Cancer is a program of the Entertainment Industry Foundation administered by the AACR. J.C. is supported by NIH Grants 5-T32 CA 009161-39 and 5-T32AI100853-04.

\section{REFERENCES}

Agalioti T, Giannou AD, Krontira AC, Kanellakis NI, Kati D, Vreka M, Pepe M, Spella M, Lilis I, Zazara DE, et al. 2017. Mutant KRAS promotes malignant pleural effusion formation. Nat Commun 8: 15205.

Ahrendt SA, Decker PA, Alawi EA, Zhu Yr YR, SanchezCespedes M, Yang SC, Haasler GB, Kajdacsy-Balla A, Demeure MJ, Sidransky D. 2001. Cigarette smoking is strongly associated with mutation of the K-ras gene in patients with primary adenocarcinoma of the lung. Cancer 92: 1525-1530.

Ali K, Soond DR, Pineiro R, Hagemann T, Pearce W, Lim EL, et al. 2014. Inactivation of $\mathrm{PI}(3) \mathrm{K}$ p110 $\delta$ breaks regulatory T-cell-mediated immune tolerance to cancer. Nature 510: 407-411.

Allen SJ, Crown SE, Handel TM. 2007. Chemokine: Receptor structure, interactions, and antagonism. Annu Rev Immunol 25: 787-820.

Almand B, Clark JI, Nikitina E, van Beynen J, English NR, Knight SC, Carbone DP, Gabrilovich DI. 2001. Increased production of immature myeloid cells in cancer patients: A mechanism of immunosuppression in cancer. J Immunol 166: 678-689.

Ancrile B, Lim KH, Counter CM. 2007. Oncogenic Ras-induced secretion of IL6 is required for tumorigenesis. Genes Dev 21: 1714-1719.

Andoh A, Takaya H, Saotome T, Shimada M, Hata K, Araki Y, Nakamura F, Shintani Y, Fujiyama Y, Bamba T. 2000. Cytokine regulation of chemokine (IL- 8, MCP-1, and RANTES) gene expression in human pancreatic periacinar myofibroblasts. Gastroenterology 119: 211-219.

Apte MV, Pirola RC, Wilson JS. 2012. Pancreatic stellate cells: A starring role in normal and diseased pancreas. Front Physiol 3: 344.

Bailey JM, Swanson BJ, Hamada T, Eggers JP, Singh PK, Caffery T, Oullette MM, Hollingsworth MA. 2008. Sonic hedgehog promotes desmoplasia in pancreatic cancer. Clin Cancer Res 14: 5995-6004.

Baines AT, Xu D, Der CJ. 2011. Inhibition of Ras for cancer treatment: The search continues. Future Med Chem 3: 1787-1808.

Baldwin GC, Gasson JC, Kaufman SE, Quan SG, Williams RE, Avalos BR, Gazdar AF, Golde DW, DiPersio JF. 1989. Nonhematopoietic tumor cells express functional GMCSF receptors. Blood 73: 1033-1037.

Baud V, Karin M. 2009. Is NF- $\mathrm{KB}$ a good target for cancer therapy? Hopes and pitfalls. Nat Rev Drug Discov 8: 3340.

Bayne LJ, Beatty GL, Jhala N, Clark CE, Rhim AD, Stanger BZ, Vonderheide RH. 2012. Tumor-derived granulocytemacrophage colony-stimulating factor regulates myeloid 
J. Cullis et al.

inflammation and $\mathrm{T}$ cell immunity in pancreatic cancer Cancer Cell 21: 822-835.

Bellone G, Turletti A, Artusio E, Mareschi K, Carbone A Tibaudi D, Robecchi A, Emanuelli G. 1999. Tumor-associated transforming growth factor $\beta$ and interleukin-10 contribute to a systemic Th2 immune phenotype in pancreatic carcinoma patients. Am J Pathol 155: 537-547.

Bellone G, Smirne C, Mauri FA, Tonel E, Carbone A, Buffolino A, Dughera L, Robecchi A, Pirisi M, Emanuelli G. 2006. Cytokine expression profile in human pancreatic carcinoma cells and in surgical specimens: Implications for survival. Cancer Immunol Immunother 55: 684-698.

Busch SE, Hanke ML, Kargl J, Metz HE, MacPherson D, Houghton AM. 2016. Lung cancer subtypes generate unique immune responses. J Immunol 197: 4493-4503.

Caetano MS, Zhang H, Cumpian AM, Gong L, Unver N, Ostrin EJ, Daliri S, Chang SH, Ochoa CE, Hanash S, et al. 2016. IL6 blockade reprograms the lung tumor microenvironment to limit the development and progression of K-ras-mutant lung cancer. Cancer Res 76: 3189-3199.

Carpagnano GE, Resta O, Foschino-Barbaro MP, Gramiccioni E, Carpagnano F. 2002. Interleukin-6 is increased in breath condensate of patients with non-small cell lung cancer. Int J Biol Markers 17: 141-145.

Chang CH, Hsiao CF, Yeh YM, Chang GC, Tsai YH, Chen YM, Huang MS, Chen HL, Li YJ, Yang PC, et al. 2013. Circulating interleukin-6 level is a prognostic marker for survival in advanced nonsmall cell lung cancer patients treated with chemotherapy. Int J Cancer 132: 1977-1985.

Chang SH, Mirabolfathinejad SG, Katta H, Cumpian AM Gong L, Caetano MS, Moghaddam SJ, Dong C. 2014 T helper 17 cells play a critical pathogenic role in lung cancer. Proc Natl Acad Sci 111: 5664-5669.

Chen JJ, Yao PL, Yuan A, Hong TM, Shun CT, Kuo ML, Lee YC, Yang PC. 2003. Up-regulation of tumor interleukin-8 expression by infiltrating macrophages: Its correlation with tumor angiogenesis and patient survival in nonsmall cell lung cancer. Clin Cancer Res 9: 729-737.

Clark CE, Beatty GL, Vonderheide RH. 2009. Immunosurveillance of pancreatic adenocarcinoma: Insights from genetically engineered mouse models of cancer. Cancer Lett 279: 1-7.

Cortez-Retamozo V, Etzrodt M, Newton A, Rauch PJ, Chudnovskiy A, Berger C, Ryan RJ, Iwamoto Y, Marinelli B, Gorbatov R, et al. 2012. Origins of tumor-associated macrophages and neutrophils. Proc Natl Acad Sci 109: 2491-2496.

Cox AD, Fesik SW, Kimmelman AC, Luo J, Der CJ. 2014. Drugging the undruggable RAS: Mission possible? Nat Rev Drug Discov 13: 828-851.

Cullis J, Siolas D, Avanzi A, Barui S, Maitra A, Bar-Sagi D. 2017. Macropinocytosis of nab-paclitaxel drives macrophage activation in pancreatic cancer. Cancer Immunol Res 5: 182-190.

Dai F, Liu L, Che G, Yu N, Pu Q, Zhang S, Ma J, Ma L, You Z. 2010. The number and microlocalization of tumor-associated immune cells are associated with patient's survival time in non-small cell lung cancer. BMC Cancer 10: 220.

Daley D, Zambirinis CP, Seifert L, Akkad N, Mohan N, Werba G, Barilla R, Torres-Hernandez A, Hundeyin M, Mani VR, et al. 2016. $\gamma \delta \mathrm{T}$ cells support pancreatic oncogenesis by restraining $\alpha \beta \mathrm{T}$ cell activation. Cell $\mathbf{1 6 6}$ : 1485 .

Delitto D, Black BS, Sorenson HL, Knowlton AE, Thomas RM, Sarosi GA, Moldawer LL, Behrns KE, Liu C, George TJ, et al. 2015. The inflammatory milieu within the pancreatic cancer microenvironment correlates with clinicopathologic parameters, chemoresistance and survival. BMC Cancer 15: 783.

Dickson RB, Kasid A, Huff KK, Bates SE, Knabbe C, Bronzert D, Gelmann EP, Lippman ME. 1987. Activation of growth factor secretion in tumorigenic states of breast cancer induced by $17 \beta$-estradiol or v-Ha-ras oncogene. Proc Natl Acad Sci 84: 837-841.

Dong ZY, Zhong WZ, Zhang XC, Su J, Xie Z, Liu SY, Tu HY, Chen HJ, Sun YL, Zhou Q, et al. 2017. Potential predictive value of TP53 and KRAS mutation status for response to PD-1 blockade immunotherapy in lung adenocarcinoma. Clin Cancer Res 23: 3012-3024.

Drake CG, Jaffee E, Pardoll DM. 2006. Mechanisms of immune evasion by tumors. Adv Immunol 90: 51-81.

Duan M, Ning Z, Fu Z, Zhang J, Liu G, Wei Q, Zheng X. 2015. Decreased IL-27 negatively correlated with Th17 cells in non-small-cell lung cancer patients. Mediators Inflamm 2015: 802939.

Ebrahimi B, Tucker SL, Li D, Abbruzzese JL, Kurzrock R. 2004. Cytokines in pancreatic carcinoma: Correlation with phenotypic characteristics and prognosis. Cancer 101: 2727-2736.

Ene-Obong A, Clear AJ, Watt J, Wang J, Fatah R, Riches JC, Marshall JF, Chin-Aleong J, Chelala C, Gribben JG, et al. 2013. Activated pancreatic stellate cells sequester $\mathrm{CD} 8^{+}$ $\mathrm{T}$ cells to reduce their infiltration of the juxtatumoral compartment of pancreatic ductal adenocarcinoma. Gastroenterology 145: 1121-1132.

Feig C, Jones JO, Kraman M, Wells RJ, Deonarine A, Chan DS, Connell CM, Roberts EW, Zhao Q, Caballero OL, et al. 2013. Targeting CXCL12 from FAP-expressing carcinoma-associated fibroblasts synergizes with anti-PD-L1 immunotherapy in pancreatic cancer. Proc Natl Acad Sci 110: 20212-20217

Feurino LW, Zhang Y, Bharadwaj U, Zhang R, Li F, Fisher WE, Brunicardi FC, Chen C, Yao Q, Min L. 2007. IL-6 stimulates Th2 type cytokine secretion and upregulates VEGF and NRP-1 expression in pancreatic cancer cells. Cancer Biol Ther 6: 1096-1100.

Finco TS, Westwick JK, Norris JL, Beg AA, Der CJ, Baldwin AS Jr. 1997. Oncogenic Ha-Ras-induced signaling activates NF- $\mathrm{\kappa B}$ transcriptional activity, which is required for cellular transformation. J Biol Chem 272: 24113-24116.

Fortis C, Foppoli M, Gianotti L, Galli L, Citterio G, Consogno G, Gentilini O, Braga M. 1996. Increased interleukin-10 serum levels in patients with solid tumours. Cancer Lett 104: 1-5.

Fossum B, Olsen AC, Thorsby E, Gaudernack G. 1995. CD8 ${ }^{+}$ $\mathrm{T}$ cells from a patient with colon carcinoma, specific for a mutant p21-Ras-derived peptide (Gly13 $\rightarrow$ Asp), are cytotoxic towards a carcinoma cell line harbouring the same mutation. Cancer Immunol Immunother 40: 165-172.

Frick VO, Rubie C, Wagner M, Graeber S, Grimm H, Kopp B, Rau BM, Schilling MK. 2008. Enhanced ENA-78 and IL-8 expression in patients with malignant pancreatic diseases. Pancreatology 8: 488-497. 
Fukuda A, Wang SC, Morris JP IV, Folias AE, Liou A, Kim GE, Akira S, Boucher KM, Firpo MA, Mulvihill SJ, et al. 2011. Stat3 and MMP7 contribute to pancreatic ductal adenocarcinoma initiation and progression. Cancer Cell 19: $441-455$

Gabrilovich DI, Velders MP, Sotomayor EM, Kast WM. 2001. Mechanism of immune dysfunction in cancer mediated by immature Gr- $1^{+}$myeloid cells. J Immunol 166: 5398-5406.

Gorelik L, Flavell RA. 2002. Transforming growth factor- $\beta$ in T-cell biology. Nat Rev Immunol 2: 46-53.

Granville CA, Memmott RM, Balogh A, Mariotti J, Kawabata S, Han W, Lopiccolo J, Foley J, Liewehr DJ, Steinberg SM, et al. 2009. A central role for Foxp $3^{+}$regulatory T cells in K-Ras-driven lung tumorigenesis. PLoS ONE 4: e5061.

Guerra C, Collado M, Navas C, Schuhmacher AJ, Hernández-Porras I, Cañamero M, Rodriguez-Justo M, Serrano M, Barbacid M. 2011. Pancreatitis-induced inflammation contributes to pancreatic cancer by inhibiting oncogeneinduced senescence. Cancer Cell 19: 728-739.

Gunderson AJ, Kaneda MM, Tsujikawa T, Nguyen AV, Affara NI, Ruffell B, Gorjestani S, Liudahl SM, Truitt M, Olson P, et al. 2016. Bruton tyrosine kinase-dependent immune cell cross-talk drives pancreas cancer. Cancer Discov 6: $270-285$

Hasegawa Y, Takanashi S, Kanehira Y, Tsushima T, Imai T, Okumura K. 2001. Transforming growth factor- $\beta 1$ level correlates with angiogenesis, tumor progression, and prognosis in patients with nonsmall cell lung carcinoma. Cancer 91: 964-971.

Hatanaka H, Abe Y, Kamiya T, Morino F, Nagata J, Tokunaga T, Oshika Y, Suemizu H, Kijima H, Tsuchida T, et al. 2000. Clinical implications of interleukin (IL)-10 induced by non-small-cell lung cancer. Ann Oncol 11: 815-819.

Herter-Sprie GS, Koyama S, Korideck H, Hai J, Deng J, Li YY, Buczkowski KA, Grant AK, Ullas S, Rhee K, et al. 2016. Synergy of radiotherapy and PD-1 blockade in Kras-mutant lung cancer. JCI Insight 1: e87415.

Holmer R, Goumas FA, Waetzig GH, Rose-John S, Kalthoff H. 2014. Interleukin-6: A villain in the drama of pancreatic cancer development and progression. Hepatobiliary Pancreat Dis Int 13: 371-380.

Hsu P, Santner-Nanan B, Hu M, Skarratt K, Lee CH, Stormon M, Wong M, Fuller SM, Nanan R. 2015. IL-10 potentiates differentiation of human induced regulatory T cells via STAT3 and Foxo1. J Immunol 195: 3665-3674.

Huang F, Wang XL, Geng Y, Li MX. 2005. Evaluation of IL-6 level in serum and bronchoalveolar lavage fluid of patients with non-small cell lung cancer (NSCLC). Xi Bao Yu Fen Zi Mian Yi Xue Za ZhiEur 21: 507-509.

Ino Y, Yamazaki-Itoh R, Shimada K, Iwasaki M, Kosuge T, Kanai Y, Hiraoka N. 2013. Immune cell infiltration as an indicator of the immune microenvironment of pancreatic cancer. Br J Cancer 108: 914-923.

Jess T, Rungoe C, Peyrin-Biroulet L. 2012. Risk of colorectal cancer in patients with ulcerative colitis: A meta-analysis of population-based cohort studies. Clin Gastroenterol Hepatol 10: 639-645.

Ji H, Houghton AM, Mariani TJ, Perera S, Kim CB, Padera R, Tonon G, McNamara K, Marconcini LA, Hezel A, et al. 2006. K-ras activation generates an inflammatory response in lung tumors. Oncogene 25: 2105-2112.
Kenkel JA, Tseng WW, Davidson MG, Tolentino L, Choi O, Bhattacharya N, Seeley ES, Winer DA, Reticker-Flynn NE, Engleman EG. 2017. An immunosuppressive dendritic cell subset accumulates at secondary sites and promotes metastasis in pancreatic cancer. Cancer Res 77: 4158-4170.

Kim BY, Gaynor RB, Song K, Dritschilo A, Jung M. 2002. Constitutive activation of NF- $\kappa \mathrm{B}$ in Ki-ras-transformed prostate epithelial cells. Oncogene 21: 4490-4497.

Koizumi M, Hiasa Y, Kumagi T, Yamanishi H, Azemoto N, Kobata T, Matsuura B, Abe M, Onji M. 2013. Increased Bcell-activating factor promotes tumor invasion and metastasis in human pancreatic cancer. PloS ONE 8: e71367.

Kordes C, Brookmann S, Haussinger D, Klonowski-Stumpe H. 2005. Differential and synergistic effects of platelet-derived growth factor- $\mathrm{BB}$ and transforming growth factor- $\beta 1$ on activated pancreatic stellate cells. Pancreas 31: 156-167.

Kubuschok B, Neumann F, Breit R, Sester M, Schormann C, Wagner C, Sester U, Hartmann F, Wagner M, Remberger $\mathrm{K}$, et al. 2006. Naturally occurring T-cell response against mutated p21 ras oncoprotein in pancreatic cancer. Clin Cancer Res 12: 1365-1372.

Kulkarni AB, Karlsson S. 1993. Transforming growth factor$\beta 1$ knockout mice. A mutation in one cytokine gene causes a dramatic inflammatory disease. Am J Pathol 143: 3-9.

Kurahara H, Shinchi H, Mataki Y, Maemura K, Noma H, Kubo F, Sakoda M, Ueno S, Natsugoe S, Takao S. 2011. Significance of M2-polarized tumor-associated macrophage in pancreatic cancer. J Surg Res 167: e211-e219.

Kusmartsev S, Gabrilovich DI. 2006. Effect of tumor-derived cytokines and growth factors on differentiation and immune suppressive features of myeloid cells in cancer. Cancer Metastasis Rev 25: 323-331.

Lee J, Horuk R, Rice GC, Bennett GL, Camerato T, Wood WI. 1992. Characterization of two high affinity human interleukin-8 receptors. J Biol Chem 267: 16283-16287.

Lee KE, Spata M, Bayne LJ, Buza EL, Durham AC, Allman D, Vonderheide RH, Simon MC. 2016. Hifla deletion reveals pro-neoplastic function of B cells in pancreatic neoplasia. Cancer Discov 6: 256-269.

Lehmann K, Janda E, Pierreux CE, Rytomaa M, Schulze A, McMahon M, Hill CS, Beug H, Downward J. 2000. Raf induces TGF $\beta$ production while blocking its apoptotic but not invasive responses: A mechanism leading to increased malignancy in epithelial cells. Genes Dev 4: 2610-2622.

Lesina M, Kurkowski MU, Ludes K, Rose-John S, Treiber M Klöppel G, Yoshimura A, Reindl W, Sipos B, Akira S, et al. 2011. Stat3/Socs3 activation by IL-6 transsignaling promotes progression of pancreatic intraepithelial neoplasia and development of pancreatic cancer. Cancer Cell 19: 456-469.

Li MO, Wan YY, Sanjabi S, Robertson AK, Flavell RA. 2006. Transforming growth factor- $\beta$ regulation of immune responses. Annu Rev Immunol 24: 99-146.

Li A, King J, Moro A, Sugi MD, Dawson DW, Kaplan J, Li G, Lu X, Strieter RM, Burdick M, et al. 2011. Overexpression of CXCL5 is associated with poor survival in patients with pancreatic cancer. Am J Pathol 178: 1340-1349.

Linard B, Bezieau S, Benlalam H, Labarrière N, Guilloux Y, Diez E, Jotereau F. 2002. A ras-mutated peptide targeted by CTL infiltrating a human melanoma lesion. J Immunol 168: $4802-4808$. 
J. Cullis et al.

Liou GY, Storz P. 2015. Inflammatory macrophages in pancreatic acinar cell metaplasia and initiation of pancreatic cancer. Oncoscience 2: 247-251.

Liou GY, Döppler H, Necela B, Krishna M, Crawford HC, Raimondo M, Storz P. 2013. Macrophage-secreted cytokines drive pancreatic acinar-to-ductal metaplasia through NF-אB and MMPs. J Cell Biol 202: 563-577.

Liou GY, Doppler H, Necela B, Edenfield B, Zhang L, Dawson DW, Storz P. 2015. Mutant KRAS-induced expression of ICAM-1 in pancreatic acinar cells causes attraction of macrophages to expedite the formation of precancerous lesions. Cancer Discov 5: 52-63.

Loetscher P, Pellegrino A, Gong JH, Mattioli I, Loetscher M, Bardi G, Baggiolini M, Clark-Lewis I. 2001. The ligands of CXC chemokine receptor 3, I-TAC, Mig, and IP10, are natural antagonists for CCR3. J Biol Chem 276: 2986-2991.

Löhr M, Schmidt C, Ringel J, Kluth M, Müller P, Nizze H, Jesnowski R. 2001. Transforming growth factor- $\beta 1$ induces desmoplasia in an experimental model of human pancreatic carcinoma. Cancer Res 61: 550-555.

Löhr M, Kloppel G, Maisonneuve P, Lowenfels AB, Luttges J. 2005. Frequency of K-ras mutations in pancreatic intraductal neoplasias associated with pancreatic ductal adenocarcinoma and chronic pancreatitis: A meta-analysis. Neoplasia 7: 17-23.

Lowenfels AB, Maisonneuve P, Cavallini G, Ammann RW, Lankisch PG, Andersen JR, Dimagno EP, AndrénSandberg A, Domellöf L. 1993. Pancreatitis and the risk of pancreatic cancer. International Pancreatitis Study Group. N Engl J Med 328: 1433-1437.

Lunardi S, Jamieson NB, Lim SY, Griffiths KL, CarvalhoGaspar M, Al-Assar O, Yameen S, Carter RC, McKay CJ, Spoletini G, et al. 2014. IP-10/CXCL10 induction in human pancreatic cancer stroma influences lymphocytes recruitment and correlates with poor survival. Oncotarget 5: 11064-11080.

Lüttges J, Reinecke-Lüthge A, Möllmann B, Menke MA, Clemens A, Klimpfinger M, Sipos B, Klöppel G. 1999. Duct changes and K-ras mutations in the disease-free pancreas: Analysis of type, age relation and spatial distribution. Virchows Arch 435: 461-468.

Mace TA, Ameen Z, Collins A, Wojcik S, Mair M, Young GS, Fuchs JR, Eubank TD, Frankel WL, Bekaii-Saab T, et al. 2013a. Pancreatic cancer-associated stellate cells promote differentiation of myeloid-derived suppressor cells in a STAT3-dependent manner. Cancer Res 73: 3007-3018.

Mace TA, Bloomston M, Lesinski GB. 2013b. Pancreatic cancer-associated stellate cells: A viable target for reducing immunosuppression in the tumor microenvironment. Oncoimmunology 2: e24891.

Mace TA, Shakya R, Pitarresi JR, Swanson B, McQuinn CW, Loftus S, Nordquist E, Cruz-Monserrate Z, Yu L, Young G, et al. 2016. IL-6 and PD-L1 antibody blockade combination therapy reduces tumour progression in murine models of pancreatic cancer. Gut doi: 10.1136/gutjnl2016-311585.

Maher J, Davies ET. 2004. Targeting cytotoxic T lymphocytes for cancer immunotherapy. Br J Cancer 91: 817-821.

Malka D, Hammel P, Maire F, Rufat P, Madeira I, Pessione F, Lévy P, Ruszniewski P. 2002. Risk of pancreatic adenocarcinoma in chronic pancreatitis. Gut 51: 849-852.
Mantovani A, Sozzani S, Locati M, Allavena P, Sica A. 2002. Macrophage polarization: Tumor-associated macrophages as a paradigm for polarized M2 mononuclear phagocytes. Trends Immunol 23: 549-555.

Mantovani A, Schioppa T, Porta C, Allavena P, Sica A. 2006. Role of tumor-associated macrophages in tumor progression and invasion. Cancer Metastasis Rev 25: 315-322.

Markowitz J, Brooks TR, Duggan MC, Paul BK, Pan X, Wei L, Abrams Z, Luedke E, Lesinski GB, Mundy-Bosse B, et al. 2015. Patients with pancreatic adenocarcinoma exhibit elevated levels of myeloid-derived suppressor cells upon progression of disease. Cancer Immunol Immunother 64: 149-159.

Marshall EA, Ng KW, Kung SH, Conway EM, Martinez VD, Halvorsen EC, Rowbotham DA, Vucic EA, Plumb AW, Becker-Santos DD, et al. 2016. Emerging roles of T helper 17 and regulatory $\mathrm{T}$ cells in lung cancer progression and metastasis. Mol Cancer 15: 67.

Mathew E, Brannon AL, Del Vecchio A, Garcia PE, Penny MK, Kane KT, Vinta A, Buckanovich RJ, di Magliano MP. 2016. Mesenchymal stem cells promote pancreatic tumor growth by inducing alternative polarization of macrophages. Neoplasia 18: 142-151.

McAllister F, Bailey JM, Alsina J, Nirschl CJ, Sharma R, Fan $\mathrm{H}$, Rattigan Y, Roeser JC, Lankapalli RH, Zhang H, et al. 2014. Oncogenic Kras activates a hematopoietic-to-epithelial IL-17 signaling axis in preinvasive pancreatic neoplasia. Cancer Cell 25: 621-637.

Means AL, Ray KC, Singh AB, Washington MK, Whitehead RH, Harris RC Jr, Wright CV, Coffey RJ Jr, Leach SD 2003. Overexpression of heparin-binding EGF-like growth factor in mouse pancreas results in fibrosis and epithelial metaplasia. Gastroenterology 124: 1020-1036.

Mielgo A, Schmid MC. 2013. Impact of tumour associated macrophages in pancreatic cancer. BMB Rep 46: 131-138.

Mitchem JB, Brennan DJ, Knolhoff BL, Belt BA, Zhu Y, Sanford DE, Belaygorod L, Carpenter D, Collins L, Piwnica-Worms D, et al. 2013. Targeting tumor-infiltrating macrophages decreases tumor-initiating cells, relieves immunosuppression, and improves chemotherapeutic responses. Cancer Res 73: 1128-1141.

Moghaddam SJ, Barta P, Mirabolfathinejad SG, AmmarAouchiche Z, Garza NT, Vo TT, Newman RA, Aggarwal BB, Evans CM, Tuvim MJ, et al. 2009. Curcumin inhibits COPD-like airway inflammation and lung cancer progression in mice. Carcinogenesis 30: 1949-1956.

Moo-Young TA, Larson JW, Belt BA, Tan MC, Hawkins WG, Eberlein TJ, Goedegebuure PS, Linehan DC. 2009. Tumor-derived TGF- $\beta$ mediates conversion of $\mathrm{CD} 4^{+} \mathrm{Foxp}^{+}{ }^{+}$regulatory $\mathrm{T}$ cells in a murine model of pancreas cancer. J Immunother 32: 12-21.

Mroczko B, Groblewska M, Gryko M, Kedra B, Szmitkowski M. 2010. Diagnostic usefulness of serum interleukin 6 (IL-6) and C-reactive protein (CRP) in the differentiation between pancreatic cancer and chronic pancreatitis. J Clin Lab Anal 24: 256-261.

Murphy PM. 1994. The molecular biology of leukocyte chemoattractant receptors. Annu Rev Immunol 12: 593-633.

Nemunaitis J, Dillman RO, Schwarzenberger PO, Senzer N, Cunningham C, Cutler J, Tong A, Kumar P, Pappen B, Hamilton C, et al. 2006. Phase II study of belagenpumatucel- $\mathrm{L}$, a transforming growth factor $\beta-2$ antisense gene- 
modified allogeneic tumor cell vaccine in non-small-cell lung cancer. J Clin Oncol 24: 4721-4730.

Nemunaitis J, Nemunaitis M, Senzer N, Snitz P, Bedell C, Kumar P, et al. 2009. Phase II trial of belagenpumatucel-L, a TGF- $\beta 2$ antisense gene modified allogeneic tumor vaccine in advanced non-small cell lung cancer (NSCLC) patients. Cancer Gene Ther 16: 620-624.

O'Hayer KM, Brady DC, Counter CM. 2009. ELR ${ }^{+}$CXC chemokines and oncogenic Ras-mediated tumorigenesis. Carcinogenesis 30: 1841-1847.

Okada S, Okusaka T, Ishii H, Kyogoku A, Yoshimori M, Kajimura N, Yamaguchi K, Kikizoe T. 1998. Elevated serum interleukin-6 levels in patients with pancreatic cancer. Jpn J Clin Oncol 28: 12-15.

Omary MB, Lugea A, Lowe AW, Pandol SJ. 2007. The pancreatic stellate cell: A star on the rise in pancreatic diseases. J Clin Invest 117: 50-59.

Ortegel JW, Staren ED, Faber LP, Warren WH, Braun DP. 2002. Modulation of tumor-infiltrating lymphocyte cytolytic activity against human non-small cell lung cancer. Lung Cancer 36: 17-25.

Pauken KE, Nelson CE, Martinov T, Spanier JA, Heffernan JR, Sahli NL, Quarnstrom CF, Osum KC, Schenkel JM, Jenkins MK, et al. 2015. Cutting edge: Identification of autoreactive $\mathrm{CD}^{+}$and $\mathrm{CD} 8^{+} \mathrm{T}$ cell subsets resistant to PD-1 pathway blockade. J Immunol 194: 3551-3555.

Principe DR, DeCant B, Diaz AM, Mangan RJ, Hwang R, Lowy A, Shetuni BB, Sreekumar BK, Chung C, Bentrem DJ, et al. 2016. PEDF inhibits pancreatic tumorigenesis by attenuating the fibro-inflammatory reaction. Oncotarget 7: 28218-28234.

Purohit A, Varney M, Rachagani S, Ouellette MM, Batra SK, Singh RK. 2016. CXCR2 signaling regulates KRAS $S^{G 12 D}$ induced autocrine growth of pancreatic cancer. Oncotarget 7: 7280-7296.

Pylayeva-Gupta Y, Lee KE, Hajdu CH, Miller G, Bar-Sagi D. 2012. Oncogenic Kras-induced GM-CSF production promotes the development of pancreatic neoplasia. Cancer Cell 21: 836-847.

Pylayeva-Gupta Y, Das S, Handler JS, Hajdu CH, Coffre M, Koralov SB, Bar-Sagi D. 2016. IL35-producing B cells promote the development of pancreatic neoplasia. Cancer Discov 6: 247-255.

Qu Z, Sun F, Zhou J, Li L, Shapiro SD, Xiao G. 2015. Interleukin-6 prevents the initiation but enhances the progression of lung cancer. Cancer Res 75: 3209-3215.

Redente EF, Higgins DM, Dwyer-Nield LD, Orme IM, Gonzalez-Juarrero M, Malkinson AM. 2010. Differential polarization of alveolar macrophages and bone marrowderived monocytes following chemically and pathogeninduced chronic lung inflammation. J Leukoc Biol 88: 159-168.

Remark R, Becker C, Gomez JE, Damotte D, Dieu-Nosjean MC, Sautès-Fridman C, Fridman WH, Powell CA, Altorki NK, Merad M, et al. 2015. The non-small cell lung cancer immune contexture. A major determinant of tumor characteristics and patient outcome. Am J Respir Crit Care Med 191: 377-390.

Rishi A, Goggins M, Wood LD, Hruban RH. 2015. Pathological and molecular evaluation of pancreatic neoplasms. Semin Oncol 42: 28-39.
Rosenberg SA, Tran E, Robbins PF. 2017. T-cell transfer therapy targeting mutant KRAS. $N$ Engl J Med 376: el1.

Rossi D, Zlotnik A. 2000. The biology of chemokines and their receptors. Annu Rev Immunol 18: 217-242.

Schmall A, Al-Tamari HM, Herold S, Kampschulte M, Weigert A, Wietelmann A, Vipotnik N, Grimminger F, Seeger W, Pullamsetti SS, et al. 2015. Macrophage and cancer cell cross-talk via CCR2 and CX3CR1 is a fundamental mechanism driving lung cancer. Am J Respir Crit Care Med 191: $437-447$.

Seo JS, Ju YS, Lee WC, Shin JY, Lee JK, Bleazard T, Lee J, Jung YJ, Kim JO, Shin JY, et al. 2012. The transcriptional landscape and mutational profile of lung adenocarcinoma. Genome Res 22: 2109-2119.

Sharma G, Whang EE, Ruan DT, Ito H. 2015. Efficacy of neoadjuvant versus adjuvant therapy for resectable pancreatic adenocarcinoma: A decision analysis. Ann Surg Oncol 22: S1229-S1237.

Shull MM, Ormsby I, Kier AB, Pawlowski S, Diebold RJ, Yin M, Allen R, Sidman C, Proetzel G, Calvin D, et al. 1992. Targeted disruption of the mouse transforming growth factor- $\beta 1$ gene results in multifocal inflammatory disease. Nature 359: 693-699.

Sparmann A, Bar-Sagi D. 2004. Ras-induced interleukin-8 expression plays a critical role in tumor growth and angiogenesis. Cancer Cell 6: 447-458.

Stambrook PJ, Maher J, Farzaneh F. 2017. Cancer immunotherapy: Whence and whither. Mol Cancer Res 15: 635-650.

Steele CW, Karim SA, Leach JD, Bailey P, Upstill-Goddard R, Rishi L, Foth M, Bryson S, McDaid K, Wilson Z, et al. 2016. CXCR2 inhibition profoundly suppresses metastases and augments immunotherapy in pancreatic ductal adenocarcinoma. Cancer Cell 29: 832-845.

Takeuchi S, Baghdadi M, Tsuchikawa T, Wada H, Nakamura T, Abe H, Nakanishi S, Usui Y, Higuchi K, Takahashi M, et al. 2015. Chemotherapy-derived inflammatory responses accelerate the formation of immunosuppressive myeloid cells in the tissue microenvironment of human pancreatic cancer. Cancer Res 75: 2629-2640.

Talar-Wojnarowska R, Gasiorowska A, Smolarz B, Romanowicz-Makowska H, Kulig A, Malecka-Panas E. 2009 Clinical significance of interleukin-6 (IL-6) gene polymorphism and IL-6 serum level in pancreatic adenocarcinoma and chronic pancreatitis. Dig Dis Sci 54: 683-689.

Tang D, Yuan Z, Xue X, Lu Z, Zhang Y, Wang H, Chen M, An Y, Wei J, Zhu Y, et al. 2012. High expression of galectin-1 in pancreatic stellate cells plays a role in the development and maintenance of an immunosuppressive microenvironment in pancreatic cancer. Int J Cancer 130: 2337-2348.

Tang D, Gao J, Wang S, Yuan Z, Ye N, Chong Y, Xu C, Jiang X, Li B, Yin W, et al. 2015. Apoptosis and anergy of T cell induced by pancreatic stellate cells-derived galectin-1 in pancreatic cancer. Tumour Biol 36: 5617-5626.

Tas F, Duranyildiz D, Oguz H, Camlica H, Yasasever V, Topuz E. 2006. Serum vascular endothelial growth factor (VEGF) and interleukin-8 (IL-8) levels in small cell lung cancer. Cancer Invest 24: 492-496.

Tateishi M, Ishida T, Mitsudomi T, Sugimachi K. 1991. Prognostic implication of transforming growth factor $\alpha$ in adenocarcinoma of the lung-An immunohistochemical study. Br J Cancer 63: 130-133. 
J. Cullis et al.

Terhune PG, Phifer DM, Tosteson TD, Longnecker DS. 1998 $\mathrm{K}$-ras mutation in focal proliferative lesions of human pancreas. Cancer Epidemiol Biomarkers Prev 7: 515-521.

Tewari N, Zaitoun AM, Arora A, Madhusudan S, Ilyas M, Lobo DN. 2013. The presence of tumour-associated lymphocytes confers a good prognosis in pancreatic ductal adenocarcinoma: An immunohistochemical study of tissue microarrays. BMC Cancer 13: 436

Tian X, Chen G, Zhou S, Henne-Bruns D, Bachem M, Kornmann M. 2012. Interactions of pancreatic cancer and stellate cells are mediated by FGFR1-III isoform expression. Hepatogastroenterology 59: 1604-1608.

Toomey D, Smyth G, Condron C, Kelly J, Byrne AM, Kay E, Conroy RM, Broe P, Bouchier-Hayes D. 2003. Infiltrating immune cells, but not tumour cells, express FasL in nonsmall cell lung cancer: No association with prognosis identified in 3-year follow-up. Int J Cancer 103: 408-412.

Topalian SL, Hodi FS, Brahmer JR, Gettinger SN, Smith DC, McDermott DF, Powderly JD, Carvajal RD, Sosman JA, Atkins MB, et al. 2012. Safety, activity, and immune correlates of anti-PD-1 antibody in cancer. N Engl J Med 366 2443-2454.

Topalian SL, Wolchok JD, Chan TA, Mellman I, Palucka K, Banchereau J, Rosenberg SA, Dane Wittrup K. 2015. Immunotherapy: The path to win the war on cancer? Cell 161: 185-186.

Trojan A, Urosevic M, Hummerjohann J, Giger R, Schanz U, Stahel RA. 2003. Immune reactivity against a novel HLAA3-restricted influenza virus peptide identified by predictive algorithms and interferon- $\gamma$ quantitative PCR. J Immunother 26: 41-46.

Tsubaki M, Yamazo Y, Yanae M, Satou T, Itoh T, Kaneko J, Kidera Y, Moriyama K, Nishida S. 2011. Blockade of the Ras/MEK/ERK and Ras/PI3K/Akt pathways by statins reduces the expression of bFGF, HGF, and TGF- $\beta$ as angiogenic factors in mouse osteosarcoma. Cytokine 54: 100-107.

Vasiliades G, Kopanakis N, Vasiloglou M, Zografos G, Margaris H, Masselou K, Kokosi E, Liakakos T. 2012. Role of the hematopoietic cytokines SCF, IL-3, GM-CSF and MCSF in the diagnosis of pancreatic and ampullary cancer. Int J Biol Markers 27: e186-e194.

von Bernstorff W, Voss M, Freichel S, Schmid A, Vogel I, Jöhnk C, Henne-Bruns D, Kremer B, Kalthoff H. 2001. Systemic and local immunosuppression in pancreatic cancer patients. Clin Cancer Res 7: 925s-932s.

Vonderheide RH, Bayne LJ. 2013. Inflammatory networks and immune surveillance of pancreatic carcinoma. Curr Opin Immunol 25: 200-205.

Waghray M, Yalamanchili M, Dziubinski M, Zeinali M, Erkkinen M, Yang H, Schradle KA, Urs S, Pasca Di Magliano M, Welling TH, et al. 2016. GM-CSF mediates mesenchymal-epithelial cross-talk in pancreatic cancer. Cancer Discov 6: 886-899.

Wang-Gillam A, Li CP, Bodoky G, Dean A, Shan YS, Jameson G, Macarulla T, Lee KH, Cunningham D, Blanc JF, et al. 2016. Nanoliposomal irinotecan with fluorouracil and folinic acid in metastatic pancreatic cancer after previous gemcitabine-based therapy (NAPOLI-1): A global, randomised, open-label, phase 3 trial. Lancet 387: 545-557.

Watt J, Kocher HM. 2013. The desmoplastic stroma of pancreatic cancer is a barrier to immune cell infiltration. Oncoimmunology 2: e26788.
Wenger FA, Jacobi CA, Zieren J, Docke W, Volk HD, Muller JM. 1999. Tumor size and lymph-node status in pancreatic carcinoma-Is there a correlation to the preoperative immune function? Langenbecks Arch Surg 384: 473-478.

Wigmore SJ, Fearon KC, Sangster K, Maingay JP, Garden OJ, Ross JA. 2002. Cytokine regulation of constitutive production of interleukin- 8 and -6 by human pancreatic cancer cell lines and serum cytokine concentrations in patients with pancreatic cancer. Int J Oncol 21: 881-886.

Wislez M, Fujimoto N, Izzo JG, Hanna AE, Cody DD, Langley RR, Tang H, Burdick MD, Sato M, Minna JD, et al. 2006. High expression of ligands for chemokine receptor CXCR2 in alveolar epithelial neoplasia induced by oncogenic kras. Cancer Res 66: 4198-4207.

Xue J, Sharma V, Hsieh MH, Chawla A, Murali R, Pandol SJ, Habtezion A. 2015. Alternatively activated macrophages promote pancreatic fibrosis in chronic pancreatitis. Nat Commun 6: 7158.

Yamaji H, Iizasa T, Koh E, Suzuki M, Otsuji M, Chang H, Motohashi S, Yokoi S, Hiroshima K, Tagawa M, et al. 2004. Correlation between interleukin 6 production and tumor proliferation in non-small cell lung cancer. Cancer Immunol Immunother 53: 786-792.

Yoon SH. 2014. Immunotherapy for non-small cell lung cancer. Tuberc Respir Dis (Seoul) 77: 111-115.

Young RP, Hopkins RJ, Christmas T, Black PN, Metcalf P, Gamble GD. 2009. COPD prevalence is increased in lung cancer, independent of age, sex and smoking history. Eur Respir J 34: 380-386.

Zambirinis CP, Levie E, Nguy S, Avanzi A, Barilla R, Xu Y, Seifert L, Daley D, Greco SH, Deutsch M, et al. 2015. TLR9 ligation in pancreatic stellate cells promotes tumorigenesis. J Exp Med 212: 2077-2094.

Zdanov S, Mandapathil M, Abu Eid R, Adamson-Fadeyi S, Wilson W, Qian J, Carnie A, Tarasova N, Mkrtichyan M, Berzofsky JA, et al. 2016. Mutant KRAS conversion of conventional $\mathrm{T}$ cells into regulatory $\mathrm{T}$ cells. Cancer Immunol Res 4: 354-365.

Zhang Y, Yan W, Collins MA, Bednar F, Rakshit S, Zetter BR, Stanger BZ, Chung I, Rhim AD, di Magliano MP. 2013. Interleukin- 6 is required for pancreatic cancer progression by promoting MAPK signaling activation and oxidative stress resistance. Cancer Res 73: 6359-6374.

Zhang Y, Yan W, Mathew E, Bednar F, Wan S, Collins MA, Evans RA, Welling TH, Vonderheide RH, di Magliano MP. 2014. $\mathrm{CD}^{+}{ }^{+} \mathrm{T}$ lymphocyte ablation prevents pancreatic carcinogenesis in mice. Cancer Immunol Res 2: 423 435.

Zhou J, Min Z, Zhang D, Wang W, Marincola F, Wang X. 2014. Enhanced frequency and potential mechanism of $B$ regulatory cells in patients with lung cancer. J Transl Med 12: 304.

Zhu Y, Knolhoff BL, Meyer MA, Nywening TM, West BL, Luo J, Wang-Gillam A, Goedegebuure SP, Linehan DC, DeNardo DG. 2014a. CSF1/CSF1R blockade reprograms tumor-infiltrating macrophages and improves response to $\mathrm{T}$-cell checkpoint immunotherapy in pancreatic cancer models. Cancer Res 74: 5057-5069.

Zhu Z, Aref AR, Cohoon TJ, Barbie TU, Imamura Y, Yang S, Moody SE, Shen RR, Schinzel AC, Thai TC, et al. 2014b. Inhibition of KRAS-driven tumorigenicity by interruption of an autocrine cytokine circuit. Cancer Discov 4: 452-465. 


\section{$\&_{\mathrm{CSH}}^{\infty} \&$ Cold Spring Harbor

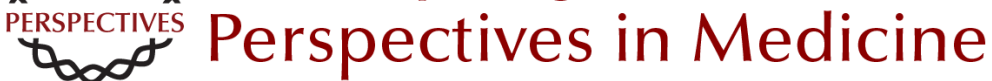

\section{Kras and Tumor Immunity: Friend or Foe?}

Jane Cullis, Shipra Das and Dafna Bar-Sagi

Cold Spring Harb Perspect Med 2018; doi: 10.1101/cshperspect.a031849 originally published online December 11, 2017

\section{Subject Collection Ras and Cancer in the 21st Century}

Targeting Ras with Macromolecules Dehua Pei, Kuangyu Chen and Hui Liao

Ras-Specific GTPase-Activating Proteins-Structures, Mechanisms, and Interactions Klaus Scheffzek and Giridhar Shivalingaiah

Ras-Mediated Activation of the Raf Family Kinases Elizabeth M. Terrell and Deborah K. Morrison

Posttranslational Modifications of RAS Proteins Ian Ahearn, Mo Zhou and Mark R. Philips

Kras in Organoids Derek Cheng and David Tuveson

KRAS: The Critical Driver and Therapeutic Target for Pancreatic Cancer Andrew M. Waters and Channing J. Der

The K-Ras, N-Ras, and H-Ras Isoforms: Unique Conformational Preferences and Implications for Targeting Oncogenic Mutants Jillian A. Parker and Carla Mattos

PI3K: A Crucial Piece in the RAS Signaling Puzzle Agata Adelajda Krygowska and Esther Castellano
MRAS: A Close but Understudied Member of the RAS Family Lucy C. Young and Pablo Rodriguez-Viciana

The Interdependent Activation of

Son-of-Sevenless and Ras Pradeep Bandaru, Yasushi Kondo and John Kuriyan

Targeting the MAPK Pathway in RAS Mutant Cancers

Sarah G. Hymowitz and Shiva Malek

Ras and the Plasma Membrane: A Complicated

Relationship

Yong Zhou, Priyanka Prakash, Alemayehu A. Gorfe, et al.

Kras and Tumor Immunity: Friend or Foe? Jane Cullis, Shipra Das and Dafna Bar-Sagi

Synthetic Lethal Vulnerabilities in KRAS-Mutant Cancers Andrew J. Aguirre and William C. Hahn

Efforts to Develop KRAS Inhibitors Matthew Holderfield

Genetically Engineered Mouse Models of K-Ras-Driven Lung and Pancreatic Tumors: Validation of Therapeutic Targets Matthias Drosten, Carmen Guerra and Mariano Barbacid

For additional articles in this collection, see http://perspectivesinmedicine.cshlp.org/cgi/collection/ 